Article

\title{
Quaternization of Composite Algal/PEI Beads for Enhanced Uranium Sorption-Application to Ore Acidic Leachate
}

\author{
Mohammed F. Hamza ${ }^{1,2}\left(\mathbb{D}\right.$, Amal E. Mubark ${ }^{2}\left(\mathbb{D}\right.$, Yuezou Wei ${ }^{1,3, *(\mathbb{0}}$, Thierry Vincent ${ }^{4}$ and \\ Eric Guibal $4, *$ (D) \\ 1 Guangxi Key Laboratory of Processing for Non-ferrous Metals and Featured Materials, School of Resources, \\ Environment and Materials, Guangxi University, Nanning 530004, China; m_fouda21@hotmail.com \\ 2 Nuclear Materials Authority, POB 530, El-Maadi, Cairo11835, Egypt; amal.mubark@yahoo.com \\ 3 Department of Nuclear Engineering and Radiological Sciences (NERS), Shanghai Jiao Tong University, \\ Shanghai 200240, China \\ 4 Polymers Composites and hybrids (PCH), IMT-Mines Ales, 6, avenue de Clavières, F-30319 Alès cedex, \\ France; thierry.vincent@mines-ales.fr \\ * Correspondence: yzwei@gxu.edu.cn (Y.W.); eric.guibal@mines-ales.fr (E.G.); \\ Tel.: +86-771-3224990 (Y.W.); +33-(0)466782734 (E.G.)
}

Received: 27 February 2020; Accepted: 28 March 2020; Published: 30 March 2020

check for updates

\begin{abstract}
The necessity to recover uranium from dilute solutions (for environmental/safety and resource management) is driving research towards developing new sorbents. This study focuses on the enhancement of $\mathrm{U}(\mathrm{VI})$ sorption properties of composite algal/Polyethylenimine beads through the quaternization of the support (by reaction with glycidyltrimethylammonium chloride). The sorbent is fully characterized by FTIR, XPS for confirming the contribution of protonated amine and quaternary ammonium groups on $\mathrm{U}(\mathrm{VI})$ binding (with possible contribution of hydroxyl and carboxyl groups, depending on the $\mathrm{pH}$ ). The sorption properties are investigated in batch with reference to pH effect (optimum value: $\mathrm{pH}$ 4), uptake kinetics (equilibrium: $40 \mathrm{~min}$ ) and sorption isotherms (maximum sorption capacity: $0.86 \mathrm{mmol} \mathrm{U} \mathrm{g}^{-1}$ ). Metal desorption (with $0.5 \mathrm{M} \mathrm{NaCl} / 0.5 \mathrm{M} \mathrm{HCl}$ ) is highly efficient and the sorbent can be reused for five cycles with limited decrease in performance. The sorbent is successfully applied to the selective recovery of $\mathrm{U}(\mathrm{VI})$ from acidic leachate of uranium ore, after pre-treatment (cementation of copper, precipitation of rare earth elements with oxalate, and precipitation of iron). A pure yellow cake is obtained after precipitation of the eluate.
\end{abstract}

Keywords: algal/Polyethylenimine beads; quaternization; uranyl sorption and desorption; sorption isotherms and uptake kinetics; metal recovery from ore leachates

\section{Introduction}

The demand of uranium for nuclear applications makes the extraction of this metal a strategic issue in terms of both economic and strategic aspects. In addition, this radionuclide is toxic and its exploitation (mining and processing) may cause significant hazards for the environment and surrounding populations. These different reasons may explain the interest of the research community for developing techniques for processing of ores (hydrometallurgy and leaching), and recovery of uranyl from aqueous solutions. Depending on the geological origin of the uranium-bearing ores, leaching may be processed using alkaline [1] or an acidic route [2]. However, in most cases the metal is extracted by acidic leaching [3-5]. The acid way is usually considered non-selective and produces multi-metal solutions such as base metals, rare earth elements (REEs), in addition to uranium. 
Separation and enrichment (the concentration effect) are thus important pieces in the design of the global ore processing.

The treatment of acidic leachates may involve a wide range of techniques including selective precipitations [6], solvent extraction [7-9], and impregnated resins [10-12]. However, sorption processes have retained more attention for the treatment of low-concentration effluents. Uranium sorption was reported using biosorbents [13-16], chelating resins [17-20], and ion-exchange resins [21-26], and functionalized inorganic supports [27-34].

The speciation of metal ions is a critical parameter that controls the affinity of the sorbents for metal species [23,35,36]. Recently, a new generation of porous material (Algal/Polyethyleneimine beads, APEI) was synthesized through the interaction of alginate and brown algae biomass with polyethylenimine (PEI) [37-39]. These materials may combine chelation and ion-exchange properties, depending on the $\mathrm{pH}$, and the metal ion (including its speciation). The concept is based on the partial extraction of alginate from brown algae in alkaline conditions, followed by the ionic interaction of carboxylate groups of alginate with protonated amine groups of PEI. This first polymer network is strengthen by the crosslinking of amine groups with glutaraldehyde and the ionotropic gelation of carboxylate groups with calcium. This second network contributes to reinforce the stability of the composite. This original method uses renewable resources (alginate and algal biomass) and environmentally friendly synthetic polymers (PEI). The synthesis procedure is remarkably simple.

However, these materials can be also used as support for functionalization with the target of increasing the reactivity and/or the selectivity of metal sorption. For example, an amidoxime derivative of APEI (AO-APEI) [40] was developed for the sorption of $\mathrm{Sr}$ (II) from aqueous solutions, including in seawater. More recently, APEI was quaternized by grafting glycidyltrimethylammonium moieties on the composite beads (Q-APEI). This sorbent was efficiently tested for the sorption of Sc(III), especially for the recovery of the metal from complex effluent issued from the treatment of red mud [41]. The properties of these materials have been fully characterized in terms of composition (elemental analysis, FTIR, and XPS), textural properties and thermogravimetric analysis.

The present study investigates the sorption properties of Q-APEI for the sorption of uranyl ions from acidic solutions. The interactions of the sorbent with uranyl ions are characterized by FTIR and XPS analysis. In a second step, the sorption properties are extensively investigated, including: $\mathrm{pH}$ effect, study of uptake kinetics and sorption isotherms at optimum $\mathrm{pH}$, metal desorption, and sorbent recycling. The last part of the work focuses on the treatment of sulfuric acid leachates of polymetallic ore. A series of pre-treatments is used for separating the metals before using Q-APEI for the recovery of uranyl ions as a yellow cake.

\section{Results and Discussion}

\subsection{Material Characterization}

\subsubsection{FTIR Analysis}

The composition of the sorbent based on algal biomass, alginate and PEI offers a large variety of functional groups: $-\mathrm{NH},-\mathrm{OH}$, and $-\mathrm{COOH}$. The presence of these groups can be identified on the FTIR spectra of APEI and Q-APEI (Figure 1). The assignment of main peaks are reported on Table S1 (see Supplementary Information). The sorption of uranyl is followed by modifications of the characteristics bands: these changes help in understanding the functional groups involved in metal binding. The figure also shows the FTIR spectra for the sorbent after uranyl desorption (to check the restauration of functional groups) and after five cycles of sorption and desorption (to evaluate the stability of the sorbent). 

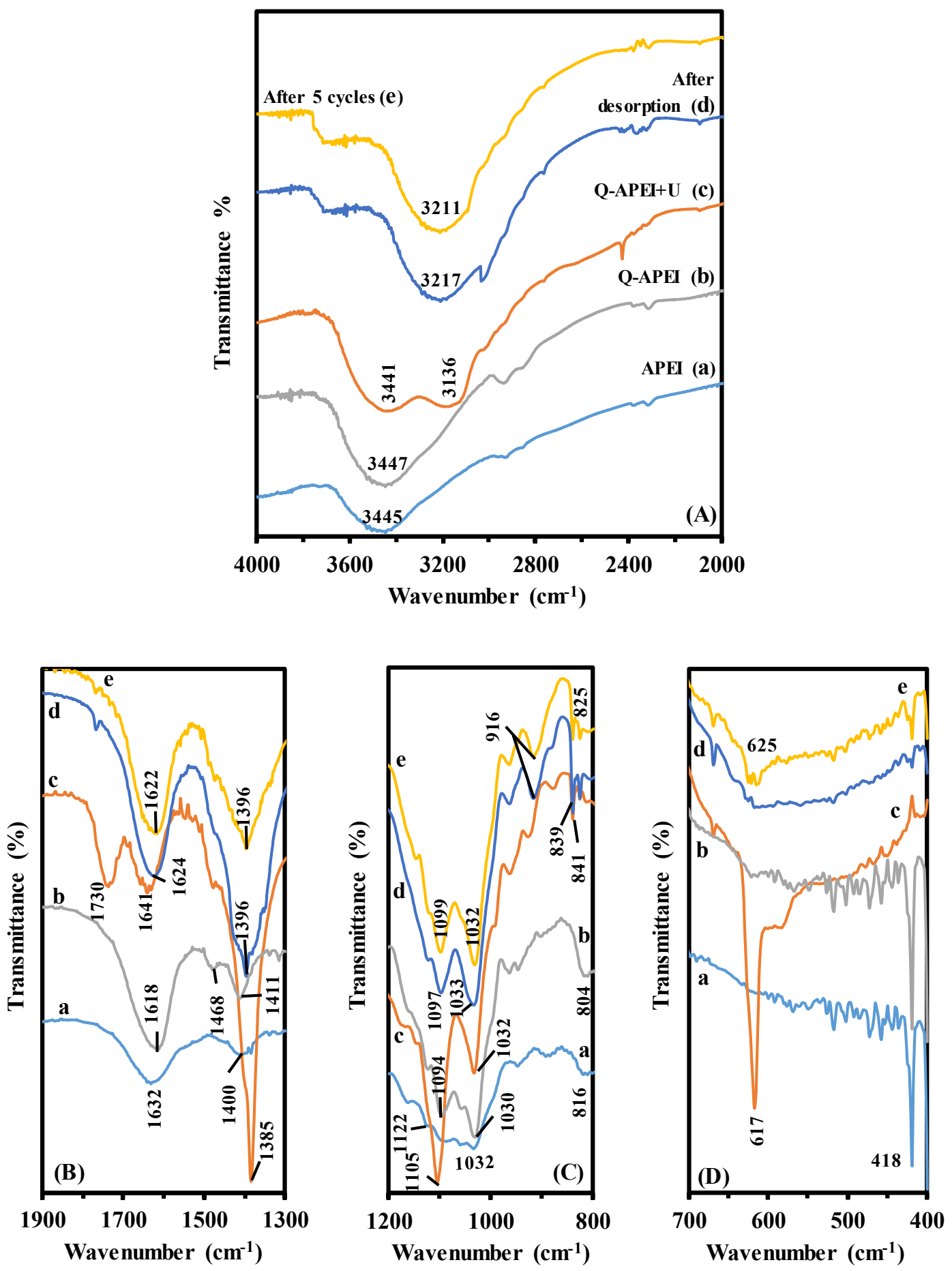

Figure 1. FTIR spectra (selected wavenumber ranges).

The first panel on Figure 1 shows the region where the stretching vibrations of $-\mathrm{OH}$ and $-\mathrm{NH}$ groups are identified (overlapping). The broad band around $3445 \mathrm{~cm}^{-1}$ is not significantly affected after quaternization (around $3447 \mathrm{~cm}^{-1}$ ). Peaks appearing around 2854 and $2930 \mathrm{~cm}^{-1}$ are assigned to C-H stretching in alkane and alkene compounds. Two small peaks appear at $2328 \mathrm{~cm}^{-1}$ and $2374 \mathrm{~cm}^{-1}$; they may be attributed to $\mathrm{O}=\mathrm{C}=\mathrm{O}$ stretching in carbon dioxide. Wang et al. [42] reported the sorption of $\mathrm{CO}_{2}$ on similar PEI-algal based materials. After uranyl sorption, substantial changes are observed: a new broad band appears at $3116 \mathrm{~cm}^{-1}$. This is probably associated with the interaction of uranyl ions with hydroxyl groups and especially amine groups. The $\mathrm{C}-\mathrm{H}$ stretching vibration poorly appears (due 
to overlapping effects of the new broad band). The band around $2350 \mathrm{~cm}^{-1}$ also disappears. The small peaks at 2328 and $2374 \mathrm{~cm}^{-1}$ re-appear after desorption (first cycle and fifth cycle). After regeneration of the resin, the two bands at 3441 and $3136 \mathrm{~cm}^{-1}$ are displaced and merged in a single broad band in the range $3217-3211 \mathrm{~cm}^{-1}$. This is a confirmation of the strong implication of $-\mathrm{NH}$ and $-\mathrm{OH}$ groups in the interactions of uranyl ions with the sorbent. In addition, the analysis of regenerated sorbent shows the appearance of a new poorly resolved band at around $3700 \mathrm{~cm}^{-1}$, this band can be assigned to alcohol functions. Therefore, the regeneration of the sorbent alters the chemical structure of the sorbent. It will be important checking how this modification can interfere with sorption performance.

A broad band appears at $1632 \mathrm{~cm}^{-1}$ on APEI $\left(1618 \mathrm{~cm}^{-1}\right.$ on Q-APEI), probably as the convolution of two signals corresponding to $\mathrm{N}=\mathrm{C}$ stretching (associated with the cross-linking of aldehydes on GA (glutaraldehyde) and amine groups on PEI) and C=O stretching. After uranyl sorption, a new strong peak appears around $1730 \mathrm{~cm}^{-1}$ (with a decrease in the width of the band at 1632-1618 $\mathrm{cm}^{-1}$ ). This peak is usually assigned to $\mathrm{C}=\mathrm{O}$ stretching in carboxylic acid and ketone groups: the binding of uranyl ions affects amine groups and modifies the spectrum to shows carboxylate-like band. The peak at $1385 \mathrm{~cm}^{-1}$ is also strongly marked after uranyl binding, this is a representative peak of $\mathrm{O}-\mathrm{H}$ bending vibration. After metal desorption and sorbent recycling, the peak at $1730 \mathrm{~cm}^{-1}$ disappears and the intensity of the peak at $1385 \mathrm{~cm}^{-1}$ strongly decreases: the sorbent is fully regenerated at the level of amine groups. Metal sorption is also marked by the formation of a strong peak at $1105 \mathrm{~cm}^{-1}$, which can be attributed to C-O stretching in secondary alcohol. The intensity of this peak decreases after metal desorption and sorbent recycling but it does not disappear. The peak at $841 \mathrm{~cm}^{-1}$, which appears after uranyl binding, is directly associated with the $\mathrm{O}=\mathrm{U}=\mathrm{O}$ vibration [43,44]. A new strong band is also observed at $617 \mathrm{~cm}^{-1}$ when uranium is sorbed and usually assigned to sulfate groups. This is a first indication that uranyl is probably bound to Q-APEI under the form of uranyl sulfate complex, or at least that sulfate anions are bound on quaternary ammonium groups of Q-APEI. After metal desorption, the strong peak disappears: sulfate being exchanged with chloride ions and being released through the desorption of uranyl sulfate ions.

\subsubsection{XPS Analysis}

XPS analysis was also used for characterizing metal binding. XPS survey spectra for APEI and Q-APEI (before and after U(VI) sorption) are reported on Figure 2. The main elements are identified associated with APEI: organic fraction containing $\mathrm{C}, \mathrm{O}$, and $\mathrm{N}$ elements. After quaternization, the intensity of $\mathrm{N} 1 \mathrm{~s}$ is more marked, and chlorine element appears $\left(\mathrm{Cl}^{-}\right.$counter anions on quaternary ammonium groups, $\mathrm{Cl} 2 \mathrm{p}$ and $\mathrm{Cl} 2 \mathrm{~s}$ ). After uranyl sorption, chlorine element disappears being replaced with S element (S $2 p$, for example) and a series of peaks assigned to $U$ elements are identified: $U 5 d_{5}$, $\mathrm{U} 5 \mathrm{p}_{3}, \mathrm{U} 4 \mathrm{f}_{7}, \mathrm{U} 4 \mathrm{f}_{5}$, and $\mathrm{U} 4 \mathrm{~d}_{5}$. The appearance of $\mathrm{S} 2 \mathrm{p}$ signal confirms the binding of sulfate anions directly on quaternary ammonium groups on the sorbent, through anion-exchange with $\mathrm{Cl}^{-}$anions. The disappearance of calcium (i.e., Ca $2 p$ ) probably means that a fraction of uranyl (essentially free cationic uranyl; i.e., $\mathrm{UO}_{2}{ }^{2+}$ ) may be bound on carboxylate groups by cation-exchange with calcium. 


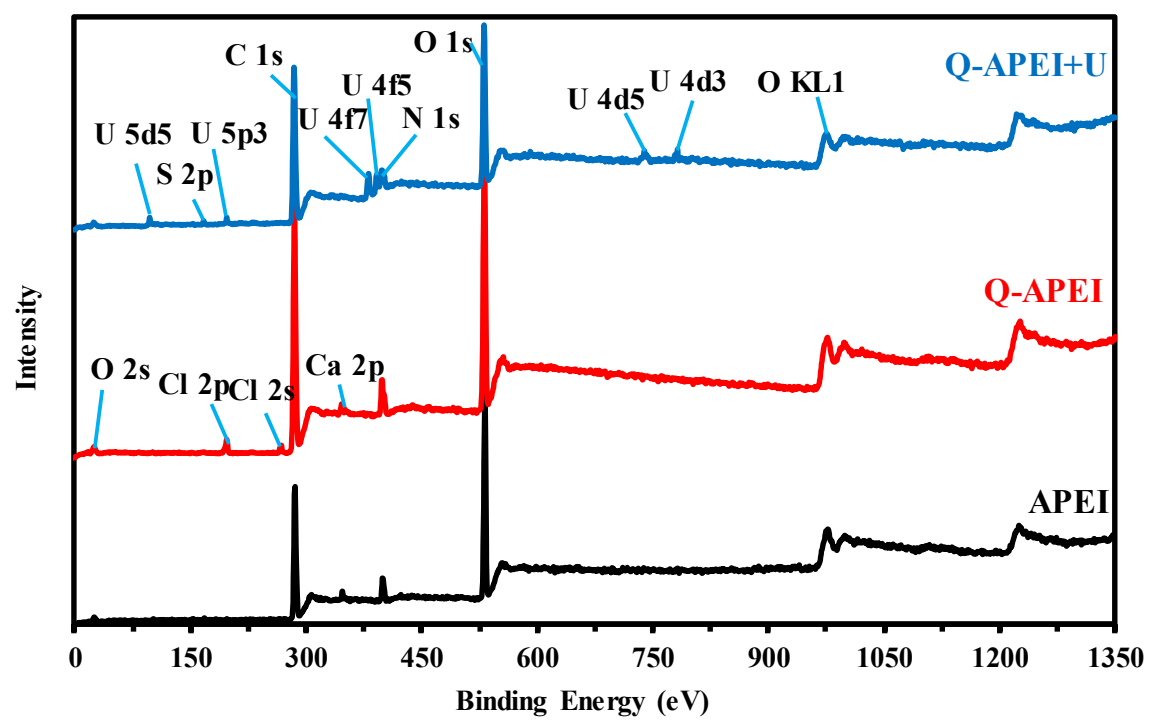

Figure 2. XPS survey of raw material (APEI), after modification (Q-APEI), and after uranium sorption (Q-APEI-U).

High-resolution spectra (HRES) (and the assignments of deconvoluted peaks) for selected signals are also shown in Tables S2 and S3. These data were previously discussed [41]. Tables S4 and S5 discuss the HRES of XPS spectra of relevant signals after uranyl binding.

The $\mathrm{C}$ 1s signals splits into four deconvoluted peaks after $\mathrm{U}(\mathrm{VI})$ binding, these peaks are different than in the XPS spectra of APEI and Q-APEI with overlapping of $\mathrm{C}(=\mathrm{O},-\mathrm{O}-\mathrm{C})$ and $\mathrm{O}-\mathrm{C}(=\mathrm{O}, \mathrm{C}-\mathrm{O})$ peaks at a binding energy $(\mathrm{BE})(\mathrm{eV})$ close to $286.97 \mathrm{eV}$. This is followed by a significant increase in intensity or atomic fraction (AF) from $0.72 \%$ and $7.75 \%$ in APEI and Q-APEI, respectively, to $15.57 \%$ after uranium binding. Other peaks corresponding to $\mathrm{C}(\mathrm{C}, \mathrm{N}, \mathrm{H}), \mathrm{C}\left(-\mathrm{NH}\right.$ or $\left.\mathrm{NH}_{2}\right)$, and $\mathrm{C}(-\mathrm{O},=\mathrm{N})$ shift to lower binding energies (compared with APEI and Q-APEI) at BEs: $283.9 \mathrm{eV}, 284.58 \mathrm{eV}$, and 285.85 $\mathrm{eV}$, respectively [45-47].

$\mathrm{N}$ 1s signal appearing as the convolution of three peaks corresponding to $\mathrm{N}-\mathrm{C}, \mathrm{N}-\mathrm{H}$ and $\mathrm{N}=\mathrm{C}$ is shifted to $398.43 \mathrm{eV}$ (compared with $399.2 \mathrm{eV}$ for APEI, and $398.44 \mathrm{eV}$ for Q-APEI). The signal representative of $\mathrm{N}_{\text {tert. }}$ [48] shifts to higher binding energy compared with Q-APEI after uranyl sorption. This means that a charge transfer occurs between uranyl ions and $\mathrm{N}$-containing ligands [49]. $\mathrm{N}_{\text {tert }}$ is shifted from $400.74 \mathrm{eV}$ in APEI, to $399.7 \mathrm{eV}$ in Q-APEI and to $398.43 \mathrm{eV}$ for N-U interaction $[50,51]$. The $\mathrm{BE}$ of $\mathrm{N}^{+}$in quaternary ammonium groups is weakly shifted after metal binding (from 401.55 to $401.65 \mathrm{eV})$.

Strong differences are observed in the profiles of $\mathrm{O} 1 \mathrm{~s}$ when comparing uranyl-bonded sorbent with the spectra of APEI and Q-APEI. The signal represents the overlapping of $\mathrm{C}=\mathrm{O}, \mathrm{C}-\mathrm{O}$, and $\mathrm{O}-\mathrm{H}$, which appears at $531.09 \mathrm{eV}$ [52-56] (instead of two peaks at around 530.5 and $532 \mathrm{eV}$ in APEI and Q-APEI). The disappearance of O-Ca peak confirms the partial ion-exchange of Ca(II) with uranyl cation (on carboxylate groups); the peak at $529.92 \mathrm{eV}$ is assigned to $\mathrm{U}=\mathrm{O}[49,57,58]$.

As reported above, the appearance of $\mathrm{S} 2 \mathrm{p}$ signal on metal-loaded sorbent at $167.25 \mathrm{eV}$ (which is assigned to sulfate groups [59-62]) means that sulfate (as well as $\mathrm{HSO}_{4}{ }^{-}$) probably binds onto the quaternary ammonium groups at the surface of the sorbent at $\mathrm{pH} 4$ (see Scheme 1, part corresponding to $\mathrm{pH} 4)$. 


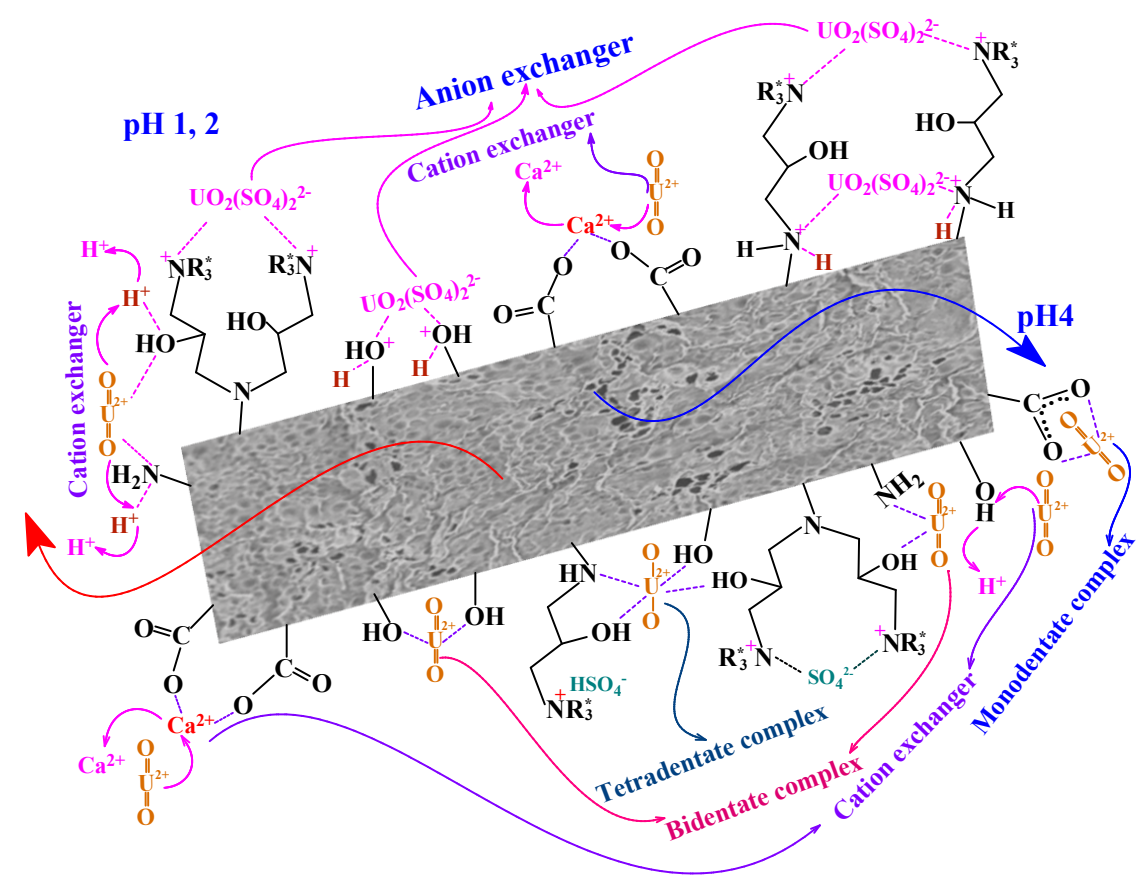

Scheme 1. Tentative mechanism for U(VI) sorption on Q-APEI.

The signals associated with Ca $2 p$ (i.e., Ca $2 p_{3 / 2}$ and $C a 2 p_{1 / 2}$ ) are significantly affected by metal sorption both in terms of BEs, full width at half maximum (FWHM) values and atomic fractions (Tables S2-S5). This confirms the ion-exchange of calcium (involved in ionotropic gelation of carboxylic groups on alginate) with cationic uranyl species for binding on carboxylate groups.

$\mathrm{U} 4 \mathrm{f}$ is deconvoluted into four peaks: $\mathrm{U} 4 \mathrm{f}_{5 / 2}$, which splits into two peaks at $389.71 \mathrm{eV}$ and $391.34 \mathrm{eV}$, while peak at $380.23 \mathrm{eV}$ is assigned to $\mathrm{U} 4 \mathrm{f}_{7 / 2}$, this attributed to free uranyl adsorption and covalent bond of N-U(VI) sorption [63]. The other peak at $384.31 \mathrm{eV}$ corresponds to the satellite peak and confirms that $\mathrm{U}$ is present under its +6 oxidation state. The deconvolution of $\mathrm{U} 4 \mathrm{~d}$ signal shows five splitting peaks at $738.35 \mathrm{eV}, 739.85 \mathrm{eV}, 737.4 \mathrm{eV}, 736.45 \mathrm{eV}$, and $742.9 \mathrm{eV}$. Other peaks, at $1272.31 \mathrm{eV}$ and $1048.93 \mathrm{eV}$, correspond to $\mathrm{U} 4 \mathrm{p} 1$ and $\mathrm{U} 4 \mathrm{p} 3$, respectively.

These results suggest that sorption occurs through different mechanisms:

(a) anionic exchange between $\mathrm{Cl}^{-}$ions on quaternary ammonium groups and anionic uranyl species [64] (at $\mathrm{pH} 1-2)$,

(b) ion-exchange with $\mathrm{Ca}^{2+}$ bound to carboxylate groups, protons on the hydroxyl and amine groups and cationic $\mathrm{UO}_{2}{ }^{2+}$ (especially at $\mathrm{pH}<\mathrm{pH}$ PZC corresponding to particle deprotonation), and/or

(c) complexation of metal species with free nitrogen or oxygen donors from PEI, hydroxyl moieties created from opened epoxy groups, and polysaccharide moieties, respectively.

\subsubsection{Determination of $\mathrm{pH}_{\mathrm{PZC}}$}

Figure S1 (see Supplementary Information) shows the application of the $\mathrm{pH}$-drift method for the evaluation of $\mathrm{pH}_{\text {PZC }}$ of APEI and Q-APEI. As expected, the $\mathrm{pH}_{\mathrm{PZC}}$ significantly increases with quaternization from 4.82-5.05 (APEI) to 6.72-6.76. The quaternization allows maintaining a positively-charged surface of the sorbent on a wider $\mathrm{pH}$ range, at least the $\mathrm{pH}$ range where uranyl sorption will be processed. At high $\mathrm{pH}$ values (except when complexed with carbonate, for example) uranyl species may precipitate (above $\mathrm{pH} 5.5$ for concentrations around $100 \mathrm{mg} \mathrm{U} \mathrm{L}^{-1} ; 0.42 \mathrm{mmol} \mathrm{U} \mathrm{L}^{-1}$ ). The comparison of recorded $\mathrm{pH}$ variations shows that the $\mathrm{pH}$ change is larger (up to $0.7 \mathrm{pH}$ unit) for Q-APEI below its $\mathrm{pH}_{\text {PZC }}$ compared with APEI (down to $0.3 \mathrm{pH}$ unit). Above $\mathrm{pH}_{\mathrm{PZC}}$, the $\mathrm{pH}$ variation is more marked for APEI (up to $2.6 \mathrm{pH}$ units at $\mathrm{pH}$ 6). The proton exchange properties are logically 
strongly affected by the quaternization of amine groups. This also means that the protonation of the sorbent will make easier the sorption of anionic metal species if present in the whole $\mathrm{pH}$ range.

The sorption is essentially constituted of alginate (alginate extracted from algal biomass, completed by the addition of supplementary alginate), polyethylenimine, and glycidyltrimethylammonium chloride. The main reactive groups present at the surface of the sorbent are:

(a) carboxylic groups (mannuronic and guluronic acid with $\mathrm{pK}_{\mathrm{a}}$ values of 3.38 and 3.65, respectively, [65]),

(b) amine groups (primary, secondary, and tertiary (1/2/1) with $\mathrm{pK}_{\mathrm{a}}$ values of $4.5,6.7$, and 11.6, respectively, [66]), and

(c) quaternary ammonium groups (with $\mathrm{pK}$ a in the range 11-12).

(d) hydroxyl groups

Therefore, the global charge can be disconnected to the individual acid-base contributions of individual reactive groups, and their potential interactions with metal species. The overall charge plays on the global properties of attraction/repulsion of sorbent surface for charged metal ions.

\subsection{Uranium Sorption}

\subsection{1. $\mathrm{pH}$ Effect}

The quaternization strongly increases the efficiency of the sorbent for binding uranyl ions in the full range of $\mathrm{pH}$ (Figure 3). The superimposition of the curves shows the good reproducibility of sorption performances. Under identical experimental conditions, the sorption capacity never exceeds $0.085 \mathrm{mmol} \mathrm{U} \mathrm{g}^{-1}$ for APEI, while for Q-APEI, the sorption capacity reaches up to $0.35 \mathrm{mmol} \mathrm{U} \mathrm{g}^{-1}$ at the optimum $\mathrm{pH}_{\mathrm{eq}}$ (i.e., 4). Despite the presence of amine groups, hydroxyls and carboxylic groups on APEI, both the crosslinking of amine groups with glutaraldehyde, and the possible interactions between protonated amine groups and carboxylic groups contribute to reduce the reactivity of functional groups. The quaternization increases the density of amine groups (from 4.15 to $6.12 \mathrm{mmol} \mathrm{N} \mathrm{g}^{-1}$ ) [41]. Branched PEI is constituted of primary/secondary/tertiary amine groups (according to the distribution: 1/2/1, with $\mathrm{pK}_{\mathrm{a}}$ values: 4.5, 6.7, and 11.6, respectively [66]). Below $\mathrm{pH} \mathrm{4}$, all of the amine groups are protonated but the steric hindrance (associated with specific interactions of PEI with glutaraldehyde and/or carboxylic groups of alginate) may limit their reactivity. The positively-charged surface of the sorbent on the whole $\mathrm{pH}$ range enhances the sorption of anionic species. At $\mathrm{pH} 1$, the competition of counter anions in the solution makes negligible uranyl binding. With increasing the $\mathrm{pH}$, the sorption capacity linearly increases: the competition of dissociated anions progressively decreases and sorption of uranyl is enhanced.

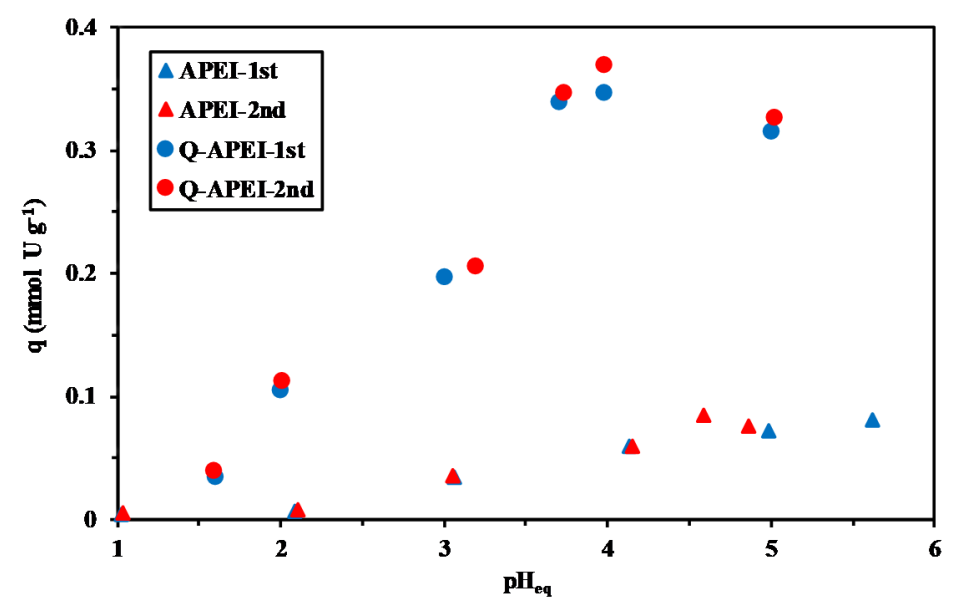

Figure 3. Effect of $\mathrm{pH}$ on $\mathrm{U}(\mathrm{VI})$ sorption using APEI and Q-APEI sorbents (Sorbent dosage (SD): $0.333 \mathrm{~g} \mathrm{~L}^{-1}$; contact time: $48 \mathrm{~h}$; agitation speed: $170 \mathrm{rpm}$; $\left.\mathrm{T}: 22 \pm 2{ }^{\circ} \mathrm{C}\right)$. 
Figure $\mathrm{S} 2$ shows the $\log _{10}$ plots of distribution ratio (D: $\mathrm{q}_{\mathrm{eq}} / \mathrm{C}_{\mathrm{eq}}, \mathrm{L} \mathrm{g}^{-1}$ ) vs. equilibrium $\mathrm{pH}$, for both APEI and Q-APEI. The curve for Q-APEI is about one order of magnitude higher than for APEI, this is a confirmation of the higher affinity of quaternized sorbent for uranyl. The two curves show two linear regions: the slope changes around $\mathrm{pH} 3.5-4$. In the acidic region, the slope is close to 0.42 for the two sorbents. This means that the binding of one uranyl will probably involve the exchange of two protons. Above $\mathrm{pH} 3.5-4$, the linear correlations are less marked and the slopes tend to decrease. When $\mathrm{pH}$ exceeds 4 , the sorption capacity tends to slightly decrease.

Figure S3a shows the speciation diagram for uranyl ions (under the experimental conditions selected for the study of $\mathrm{pH}$ effect). Precipitation may occur at $\mathrm{pH}$ higher than 5 . Further experiments have been performed at $\mathrm{pH} 4$ (optimum $\mathrm{pH}$, with no precipitation of $\mathrm{U}(\mathrm{VI})$ ). At low $\mathrm{pH}$ (i.e., $\mathrm{pH} 1$ ), uranyl is essentially present as a neutral species (i.e., $\mathrm{UO}_{2} \mathrm{SO}_{4}, \approx 65 \%$ ), while cationic free $\mathrm{UO}_{2}{ }^{2+}$ represents about $21 \%$ and anionic species (i.e., $\mathrm{UO}_{2}\left(\mathrm{SO}_{4}\right)_{2}{ }^{2-}$ ) counts for less than $14 \%$. As the $\mathrm{pH}$ increases (above $\mathrm{pH} 2$ and up to $\mathrm{pH} 4$ ), anionic uranyl species disappears, and the fraction of neutral uranyl sulfate strongly decreases while progressively uranium dioxide begins to predominate (up to $73 \%$ ). Above $\mathrm{pH} 4$ and up to $\mathrm{pH} 5$ (where $\mathrm{U}(\mathrm{VI})$ begins to precipitate) free uranyl fraction strongly decreases while hydrolyzed and polynuclear hydrolyzed species appear (mainly as $\left(\mathrm{UO}_{2}\right)_{2}(\mathrm{OH})_{2}{ }^{2+}$, $\left(\mathrm{UO}_{2}\right)_{3}(\mathrm{OH})_{5}{ }^{+}, \mathrm{UO}_{2}(\mathrm{OH})^{+}$, or $\left.\left(\mathrm{UO}_{2}\right)_{4}(\mathrm{OH})_{7}^{+}\right)$. The increase in sorption properties with $\mathrm{pH}$ up to 4 , the stoichiometric exchange (i.e., slope of $\log _{10} \mathrm{D}$ vs. $\mathrm{pH}_{\mathrm{eq}}$ ), the predominance of free uranyl species $\left(\mathrm{UO}_{2}{ }^{2+}\right)$ in this $\mathrm{pH}$ range, tend to demonstrate that uranyl sorption occurs through ion exchange of $\mathrm{UO}_{2}{ }^{2+}$ with protons on amines and hydroxyls groups. The presence of sulfate on the sorbent (identified by XPS analysis) is probably associated to the direct binding of sulfate anions onto quaternary ammonium groups or through interaction with uranyl bound to the sorbent.

The variation of $\mathrm{pH}$ with uranyl sorption (as appearing on Figure S4) is negligible for APEI sorbent up to $\mathrm{pH}$ 5. Above $\mathrm{pH} 5$, uranyl precipitation logically causes $\mathrm{pH}$ decrease. For Q-APEI sorbent, $\mathrm{pH}$ variation is negligible between $\mathrm{pH} 2$ and 3 and above $\mathrm{pH} 3$, the sorption of uranyl tends to decrease the $\mathrm{pH}$ due to proton release (proton exchange with uranyl) and the formation of hydrolyzed species (which may be bound on the resin).

Table S6 compares the semi-quantitative EDX analyses of Q-APEI loaded with uranyl at different $\mathrm{pH}$ values. In strong acid solutions (i.e., $\mathrm{pH} 1$ controlled with sulfuric acid) the sorbent is strongly protonated with relatively high atomic fractions for $\mathrm{Cl}$ (i.e., 2.56\%) and $\mathrm{S}$ ((i.e., $8.6 \%$, as sulfate) while $\mathrm{U}$ content does not exceed $0.3 \%$. With the $\mathrm{pH}$ augmentation, the $\mathrm{U}$ content progressively increases up to $2.79 \%-2.9 \%$ at $\mathrm{pH} 4$ and $\mathrm{pH} 5$, respectively. At $\mathrm{pH} 6$, $\mathrm{U}$ content decreases to $0.92 \%$. The level of $\mathrm{Cl}$ slightly varies between $0.5 \%$ and $0.84 \%$ while $\mathrm{S}$ content remains stable (around $3.0 \%-2.7 \%$ ) between $\mathrm{pH} 2$ and 5 and decreases to $1.9 \%$ at $\mathrm{pH} 6$. Sulfate content varies due to direct binding on protonated groups in acidic solutions, while at intermediary $\mathrm{pH}$ the presence of sulfate is probably associated with the binding of uranyl sulfate or the binding of sulfate on uranyl bonded on the sorbent.

\subsubsection{Sorption Mechanism}

From the data of FTIR, XPS, slope analysis of $\log _{10} \mathrm{D}$ vs. $\mathrm{pH}_{\mathrm{eq}}$, and sorption profiles, the suggested mechanism can be discussed at two different $\mathrm{pH}$ values: acidic $\mathrm{pH}$ (at $\mathrm{pH} 1-2$ ) and mild acidic medium (at $\mathrm{pH} 4$ ). At $\mathrm{pH} 1-2$, the speciation of uranyl shows the predominance of anionic uranyl sulfate species $\left(\left(\mathrm{UO}_{2}\left(\mathrm{SO}_{4}\right)_{2}{ }^{2-}\right)\right.$, which could be sorbed onto the sorbent through anion-exchange with chloride ions bond on quaternized sites, on protonated amines and hydroxyls protonated groups. This electrostatic attraction mechanism can explain the relatively higher sorption capacities observed for Q-APEI compared with APEI. On the other hand, the cationic free uranyl species binds with the sorbent by cation exchange with protons (from amines, and hydroxyls) and $\mathrm{Ca}^{2+}$ ions from carboxylate groups (see Scheme 1). At pH 4, the sorption of $\mathrm{U}(\mathrm{VI})$ onto Q-APEI might be confirmed by either complexation reaction through electron donating acceptor (mono-, bi-, and tetradentate complexes) and cationic exchanger mechanism depending on the groups on the sorbent and the $\mathrm{pH}$. At experimental $\mathrm{pH}$ values, the main uranyl species found in the solution is $\mathrm{UO}_{2}{ }^{2+}$ (and other species with lower percentage, 
such as $\left.\mathrm{UO}_{2} \mathrm{OH}^{+},\left(\mathrm{UO}_{2}\right)_{2}(\mathrm{OH})_{2}{ }^{2+}\right)$. The negatively charged uranyl species $\left(\mathrm{UO}_{2}\left(\mathrm{SO}_{4}\right)_{2}{ }^{2-}\right)$ becomes progressively negligible at higher acidic $\mathrm{pH}$ values.

From the FTIR analysis of Q-APEI, before and after loading with uranyl ions, it is evident that the main sorption mechanism performed with $\mathrm{OH}, \mathrm{NH}$, and $\mathrm{COO}^{-}$by complexation reaction and with QA groups by anion exchange reaction. FTIR analysis of loaded sorbent shows that the broad band (overlapping of hydroxyl and amine stretching vibrations) shifts from 3445 to $3136 \mathrm{~cm}^{-1}$. A new peak also appears at $3441 \mathrm{~cm}^{-1}$. These observations confirm that $\mathrm{OH}$ and $\mathrm{NH}$ groups contribute to $\mathrm{U}(\mathrm{VI})$ sorption. The peak assigned to carboxylic acid is shifted from 1385 to $1411 \mathrm{~cm}^{-1}$, meaning that the environment of carboxylic groups is also affected by uranyl binding. The changes in the environment of $\mathrm{C}=\mathrm{N}$ (shifted from 1618 to $1641 \mathrm{~cm}^{-1}$ ) and the appearance of another peak, assigned to $\mathrm{C}=\mathrm{O}$ of carboxylic acid salt, at $1730 \mathrm{~cm}^{-1}$, emphasize the contribution of these groups in uranyl binding. This is also confirmed by the shifts of C-O and C-N peaks from 1094 and $1030 \mathrm{~cm}^{-1}$ to 1105 and $1032 \mathrm{~cm}^{-1}$ after metal uptake. The new peak appearing at $617 \mathrm{~cm}^{-1}$ can be attributed to sulfate groups: this may proceed through the binding of uranyl sulfate complex and the direct binding of sulfate or hydrogen sulfate ions onto quaternized groups.

From the XPS survey of loaded sorbent, the disappearance of $\mathrm{Ca}$ and $\mathrm{Cl}$ confirm the ion-exchange mechanisms, as reported above. The splitting of $U$ f fo $U 4 f_{5 / 2}$ (two splitting peaks) and $U 4 f_{7 / 2}$, at lower values than usual, confirms that two types of binding occurred on the sorbent (probably through the formation of U-N and U-O bonds). This may be correlated to the shifts of the $\mathrm{N}_{\text {tert }}$ and $\mathrm{N}^{+}$peaks associated with either complexation and anion exchange mechanisms, respectively.

\subsubsection{Uptake Kinetics}

Figure 4 shows that the equilibrium is reached under selected experimental conditions within 30-40 $\mathrm{min}$. The mesoporous structure of the sorbent [41] may explain the readily transfer of metal ions through the sorbent. Sorption may be controlled by the resistance to film diffusion, the resistance to intraparticle diffusion but also by the proper reaction rate. Table S7 reports the equation of these models.

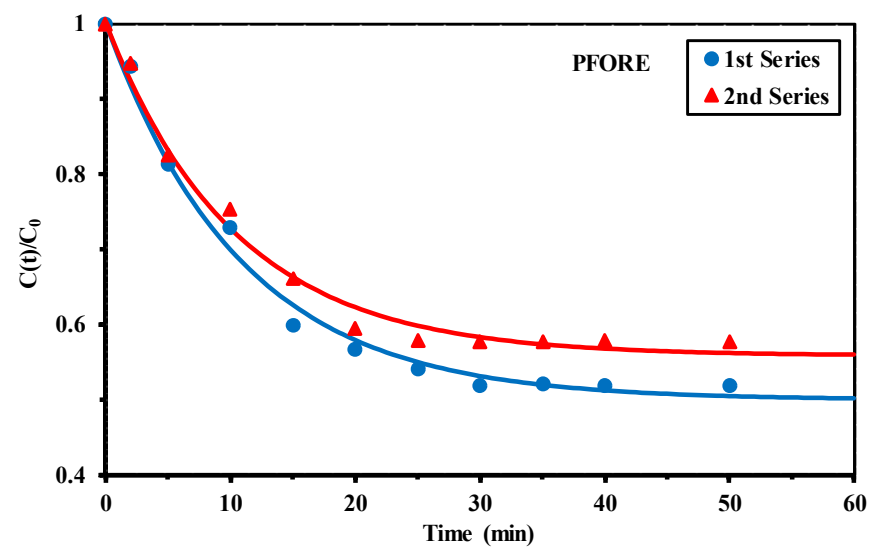

Figure 4. U(VI) uptake kinetics using Q-APEI sorbent-Modeling with the pseudo-first order rate equation (PFORE) (SD: $0.3 \mathrm{~g} \mathrm{~L}^{-1} ; \mathrm{pH}_{0}: 4 ; \mathrm{pH}_{\mathrm{eq}}$ : 3.79-3.71; $\mathrm{C}_{0}: 0.214 \mathrm{mmol} \mathrm{U} \mathrm{L}^{-1}$ and $0.249 \mathrm{mmol} \mathrm{U} \mathrm{L}^{-1}$ for the 1st and 2nd series, respectively; agitation speed: $170 \mathrm{rpm} ; \mathrm{T}: 22 \pm 2{ }^{\circ} \mathrm{C}$ ).

The fast kinetics suggests that the resistance to intraparticle diffusion does not represent the main controlling step. In Figure 4, the solid lines show the fits of experimental profiles with the pseudo-first order rate equation (PFORE); the modeling of kinetics with the PSORE (pseudo-second order rate equation) and RIDE (resistance to intraparticle diffusion equation-Crank equation) are represented in Figure S6. The PSORE fails to fit the equilibrium: overestimation of the equilibrium time with the sorption continuing above $50 \mathrm{~min}$. This is confirmed by the large difference in the experimental and calculated (overestimated) values of the sorption capacity at equilibrium (Table 1). The RIDE (i.e., Crank equation) generally respects the shape of kinetic profiles, but the determination coefficients are 
much smaller than those obtained with the PFORE. However, this model can be used for evaluating the diffusion coefficient $\left(D_{\text {eff }}, \mathrm{m}_{2} \mathrm{~min}^{-1}\right)$ for uranyl through Q-APEI: $D_{\text {eff }}$ varies between $2.6 \times 10^{-8}$ and $3.3 \times 10^{-8} \mathrm{~m}^{2} \mathrm{~min}^{-1}$. These values are comparable to the free diffusivity of uranyl in water (i.e., $2.56 \times 10^{-8} \mathrm{~m}^{2} \mathrm{~min}^{-1}$, [67]). This confirms the weak impact of resistance to intraparticle diffusion on the control of kinetic profiles and this is fully consistent with the average size of pores (i.e., 183-230 $\AA$, [60]), which is much larger than the size of hydrated uranyl $\left(\mathrm{UO}_{2}\left(\mathrm{H}_{2} \mathrm{O}\right)_{5}{ }^{2+}, 1.08 \AA\right.$ ). The PFORE slightly overestimates the sorption capacity at equilibrium: $0.358-0.365$ vs. $0.343-0.349 \mathrm{mmol} \mathrm{U} \mathrm{g}^{-1}$.

Table 1. Parameters of models for U(VI) uptake kinetics.

\begin{tabular}{cccc}
\hline Model & Parameter & $\begin{array}{c}\text { Fitted Value } \\
\text { First Series }\end{array}$ & $\begin{array}{c}\text { Fitted Value } \\
\text { Second Series }\end{array}$ \\
\hline Experimental & $\mathrm{q}_{\mathrm{eq}}\left(\mathrm{mmol} \mathrm{U} \mathrm{g}^{-1}\right)$ & 0.343 & 0.349 \\
\hline \multirow{2}{*}{ PFORE } & $\mathrm{q}_{\mathrm{eq}, 1}\left(\mathrm{mmol} \mathrm{U} \mathrm{g}^{-1}\right)$ & 0.358 & 0.365 \\
& $\mathrm{k}_{1} \times 10^{2}\left(\mathrm{~min}^{-1}\right)$ & 9.19 & 9.61 \\
& $\mathrm{R}^{2}$ & 0.992 & 0.989 \\
\hline \multirow{2}{*}{ PSORE } & $\mathrm{q}_{\mathrm{eq}, 2}\left(\mathrm{mmol} \mathrm{U} \mathrm{g}^{-1}\right)$ & 0.451 & 0.455 \\
& $\mathrm{k}_{2} \times 10^{2}\left(\mathrm{Lmol}^{-1} \mathrm{~min}^{-1}\right)$ & 20.2 & 21.3 \\
& $\mathrm{R}^{2}$ & 0.980 & 0.976 \\
\hline \multirow{2}{*}{$\mathrm{RIDE}$} & $\mathrm{D}_{\mathrm{e}} \times 10^{8}\left(\mathrm{~m}^{2} \mathrm{~min}^{-1}\right)$ & 2.59 & 3.28 \\
& $\mathrm{R}^{2}$ & 0.969 & 0.967 \\
\hline
\end{tabular}

The apparent rate coefficient is in the range: 9.19-9.61 $\times 10^{-2} \mathrm{~m}^{2} \mathrm{~min}^{-1}$. The preference of the fit of experimental kinetic profile with the PFORE (compared with pseudo-second order rate equation, PSORE) is consistent with the suspected nature of the interaction mode (ion-exchange compared chelation mechanism).

\subsubsection{Sorption Isotherms}

Figure 5 compares $\mathrm{U}(\mathrm{VI})$ sorption isotherms at $\mathrm{pH} 4$ for APEI and Q-APEI sorbents. Sorption capacity is plotted as a function of residual metal concentration in the solution. The experimental profiles are fitted with the Langmuir, Freundlich, and Sips equations. Table S8 summarizes the equations used for modeling sorption isotherms. Table 2 summarizes the parameters of the models used for fitting sorption isotherms. The shape of the sorption isotherms are characterized by a steep initial slope followed a plateau. This asymptotic trend is consistent with the Langmuir and Sips equations, contrary to the Freundlich equation that supposes an exponential trend. This is confirmed by the poor fit of experimental profile at high residual metal concentration (overestimation above $1.3 \mathrm{mmol} \mathrm{U} \mathrm{L} \mathrm{L}^{-1}$ ), and in the intermediary range of concentration (underestimation between 0.42 and $1 \mathrm{mmol} \mathrm{U} \mathrm{L}^{-1}$ ). In the case of APEI, the fitted curves approaches much better the experimental profile. The Sips equation incorporates a third-adjusting parameter. It is thus expected that the three-parameter equation best fits experimental data. Actually, this is not really the case here: the improvement in the quality of the fit with the Sips is not significant. 


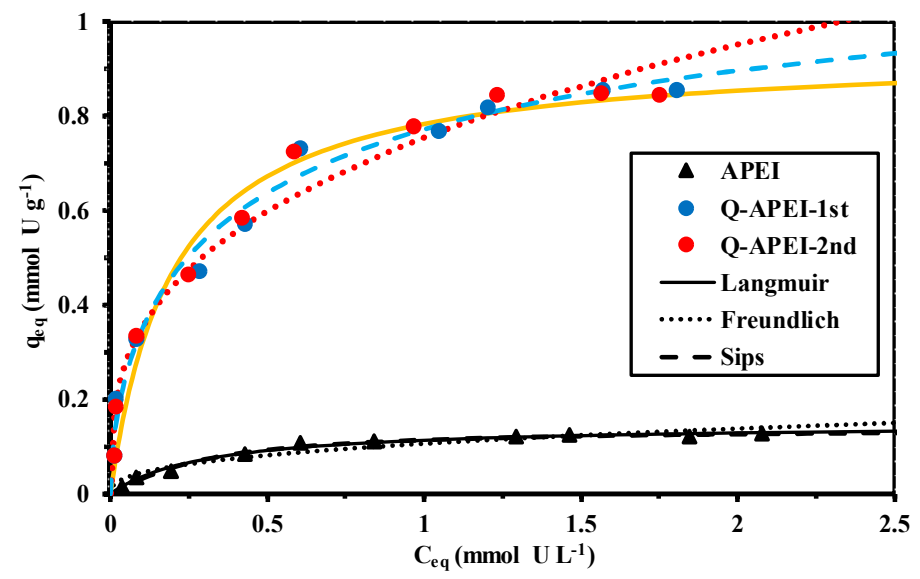

Figure 5. U(VI) sorption isotherms at $\mathrm{pH} 4$ using APEI and Q-APEI-Modeling with the equations of Langmuir, Freundlich, and Sips (SD: $0.375 \mathrm{~g} \mathrm{~L}^{-1} ; \mathrm{pH}_{0}$ : 4; $\mathrm{pH}_{\mathrm{eq}}$ : 3.87-3.69 for Q-APEI and 4.19-3.97 for APEI; $\mathrm{C}_{0}$ : 0.04-2.13 mmol U L ${ }^{-1}$; agitation speed: $170 \mathrm{rpm}$; contact time: $48 \mathrm{~h}$; $\mathrm{T}: 22 \pm 2{ }^{\circ} \mathrm{C}$ ).

Table 2. Parameters of models for U(VI) sorption isotherms.

\begin{tabular}{cccc}
\hline Model & Parameter & APEI & Q-APEI \\
\hline Experimental & $\mathrm{q}_{\mathrm{m}}\left(\mathrm{mmol} \mathrm{U} \mathrm{g}^{-1}\right)$ & 0.127 & 0.855 \\
\hline Langmuir & $\mathrm{q}_{\mathrm{m}, \mathrm{L}}\left(\mathrm{mmol} \mathrm{U} \mathrm{g}^{-1}\right)$ & 0.150 & 0.938 \\
& $\mathrm{~b}_{\mathrm{L}}\left(\mathrm{L} \mathrm{mmol}^{-1}\right)$ & 3.16 & 5.06 \\
& $\mathrm{R}^{2}$ & 0.988 & 0.976 \\
\hline Freundlich & $\mathrm{k}_{\mathrm{F}}$ & 0.106 & 0.754 \\
& $\mathrm{n}_{\mathrm{F}}$ & 2.67 & 2.99 \\
& $\mathrm{R}^{2}$ & 0.915 & 0.969 \\
\hline Sips & $\mathrm{q}_{\mathrm{m}, \mathrm{S}}\left(\mathrm{mmol} \mathrm{U} \mathrm{g}^{-1}\right)$ & 0.140 & 1.297 \\
& $\mathrm{~b}_{\mathrm{S}}\left(\mathrm{L} \mathrm{mmol}^{-1}\right)$ & 4.77 & 1.47 \\
& $\mathrm{n}_{\mathrm{S}}$ & 0.834 & 1.65 \\
& $\mathrm{R}^{2}$ & 0.986 & 0.984 \\
\hline
\end{tabular}

The sorption of uranyl is strongly improved by quaternization: maximum sorption capacity increases from 0.13 to $0.85 \mathrm{mmol} \mathrm{U} \mathrm{g}^{-1}$. This six-fold increase clearly demonstrates the highly efficient functionalization of the support, which is not simply correlated to the increase of amine groups (from 4.15 to $6.12 \mathrm{mmol} \mathrm{N} \mathrm{g}^{-1}$; i.e., about $+50 \%$ ). At saturation of the sorbent, the molar ratio between $\mathrm{U}$ and $\mathrm{N}$ is close to 0.139 . This molar ratio is not consistent with the expected stoichiometric ratio (two protons from reactive groups per bound uranyl). This means that all the amine groups are not involved in metal sorption. The increase in nitrogen after quaternization is close to $2 \mathrm{mmol} \mathrm{N} \mathrm{g}^{-1}$. Taking into account the stoichiometric molar ratio for the interaction of uranyl with the sorbent (i.e., two protonated amine groups per bound uranyl) this means that, at saturation, the ratio 2:1 is respected for the binding of one uranyl to two quaternary ammonium groups immobilized per gram of sorbent. It is noteworthy that the affinity coefficient (i.e., $b_{L}$ ) is higher for Q-APEI compared with APEI: the quaternization improves the efficiency of the sorbent not only in terms of maximum sorption capacity (asymptote of the sorption isotherms) but also in terms of affinity (initial slope of the curve).

Table 3 compares the sorption performance for $\mathrm{U}(\mathrm{VI})$ using different sorbents. The sorbent Q-APEI shows sorption properties comparable to those of the most efficient sorbents taking into account both the kinetic and the equilibrium criteria. Some specific new resins (functionalized with picolylamine groups, for example, [68]) and amidoximated sorbents [31,69,70] show higher maximum sorption capacities. Except these highly-efficient sorbents, Q-APEI shows promising properties. The ability of the metal-loaded material to be eluted and the sorbent to be recycled should be demonstrated for justifying these perspectives. It is noteworthy that FTIR analysis after five cycles of sorption and 
desorption showed some punctual differences but the general structure of the sorbent did not appear to be drastically changed.

Table 3. Comparison of sorbents for U(VI) recovery in acidic solutions (sorption performances: optimum $\mathrm{pH}$, equilibrium time, and Langmuir constants).

\begin{tabular}{|c|c|c|c|c|c|}
\hline Sorbent & $\mathrm{pH}$ & $\begin{array}{c}t_{\text {eq }} \\
(\mathrm{min})\end{array}$ & $\begin{array}{c}\mathrm{qm}_{\mathrm{m}, \mathrm{L}} \\
\left(\mathrm{mmol} \mathrm{U} \mathrm{g}^{-1}\right)\end{array}$ & $\begin{array}{c}\mathrm{b}_{\mathrm{L}} \\
\left(\mathrm{L} \mathrm{mmol} \mathbf{l}^{-1}\right)\end{array}$ & Ref. \\
\hline Sargassum & 4 & 180 & 2.40 & 0.170 & [71] \\
\hline $\mathrm{Algal} /$ yeast $/ \mathrm{SiO}_{2}$ & 4 & 180 & 0.210 & 7.14 & [72] \\
\hline Grapefruit peel & 5 & 90 & 0.592 & 7.45 & [73] \\
\hline Rice husk & 4 & 320 & 0.190 & 23.6 & [74] \\
\hline Landoltia punctata & $4-5$ & 1440 & 0.305 & 2.36 & [75] \\
\hline Eucalytus wood biochar & 5.5 & 20 & 0.114 & 5.95 & [76] \\
\hline Sugar beet pulp & 8 & 120 & 0.086 & 6.43 & [77] \\
\hline Amidoximated marine mycelium & 5 & 120 & 1.56 & 0.378 & [70] \\
\hline Tulsion $\mathrm{CH}-96$ & 3-4 $\mathrm{M} \mathrm{HNO}_{3}$ & 600 & 0.294 & 1.48 & [78] \\
\hline Amberlite CG-400 & 3.5 & 360 & 0.472 & 21.9 & [79] \\
\hline Phosphorus PStyr/DVB & 5 & 240 & 0.378 & 8.33 & [18] \\
\hline DETA-magnetic chitosan & 3.5 & 120 & 0.274 & 295 & [80] \\
\hline Carminic acid impregnated resin & 5 & 120 & 0.798 & 29.2 & [11] \\
\hline D2EHPA-impregnated polymer beads & 4 & 180 & 0.079 & 5.24 & [12] \\
\hline Amberlite IRA-402 & 3 & 90 & 0.895 & 11.9 & [81] \\
\hline Picolylamine funct. resin & 5.3 & 120 & 2.31 & 164 & [68] \\
\hline Amidoximated MCM-41 $\mathrm{SiO}_{2}$ & 5 & 40 & 1.86 & 8.5 & [69] \\
\hline Amidoximated MCM-41 $\mathrm{SiO}_{2}$ & 5 & 90 & 1.62 & 225 & [31] \\
\hline Phosphonate/MoS 2 & 5.5 & 360 & 0.949 & 9.52 & [82] \\
\hline Porous hydroxyapatite & 3.0 & 30 & 0.468 & 1113 & [83] \\
\hline Carboxylated-Zn-MOF & 4 & 60 & 0.544 & 11.2 & [84] \\
\hline $\begin{array}{l}\text { Amidoxime funct. catechol } \\
\text { iron oxide NPs }\end{array}$ & 6.5 & 180 & 0.256 & 9.52 & [85] \\
\hline APEI & 4 & - & 0.150 & 3.16 & This work \\
\hline Q-APEI & 4 & 40 & 0.938 & 5.06 & This work \\
\hline
\end{tabular}

\subsubsection{Uranium Desorption and Sorbent Recycling}

In order to elute uranium from metal-loaded sorbent, an acidic solution of sodium chloride was selected. The batch desorption of uranyl ions was tested for evaluating desorption kinetics (Figure 6 and Table 4) and recycling performances (Table 5). Metal desorption is a fast process: $30 \mathrm{~min}$ of contact are sufficient for achieving the complete desorption of uranyl, under selected experimental conditions. These kinetic profiles are slightly more favorable than the uptake kinetics. The kinetic profiles are finely fitted by the PFORE (Table 4), the PSORE-simulated curve does not reach the complete desorption of uranyl. The apparent rate coefficient for desorption (according PFORE model) is of the same order of magnitude than the corresponding apparent rate coefficient for sorption: around $0.08 \mathrm{~min}^{-1} \mathrm{vs}$. around $0.09 \mathrm{~min}^{-1}$, while the SD was substantially increased $0.85 \mathrm{~g} \mathrm{~L}^{-1}$ compared with uptake kinetics (i.e., $0.3 \mathrm{~g} \mathrm{~L}^{-1}$ ). This confirms that the main mechanisms of desorption (as well as sorption) is associated to an ion-exchange process.

Table 5 confirms the remarkable stability of the sorbent in terms of sorption and desorption efficiencies. A very limited decrease is observed for uranium uptake (less than $1 \%$ ) and metal desorption (less than $2 \%$ ). This confirms the efficient regeneration of the sorbent after one and five cycles as shown by FTIR characterization (Figure 1). 

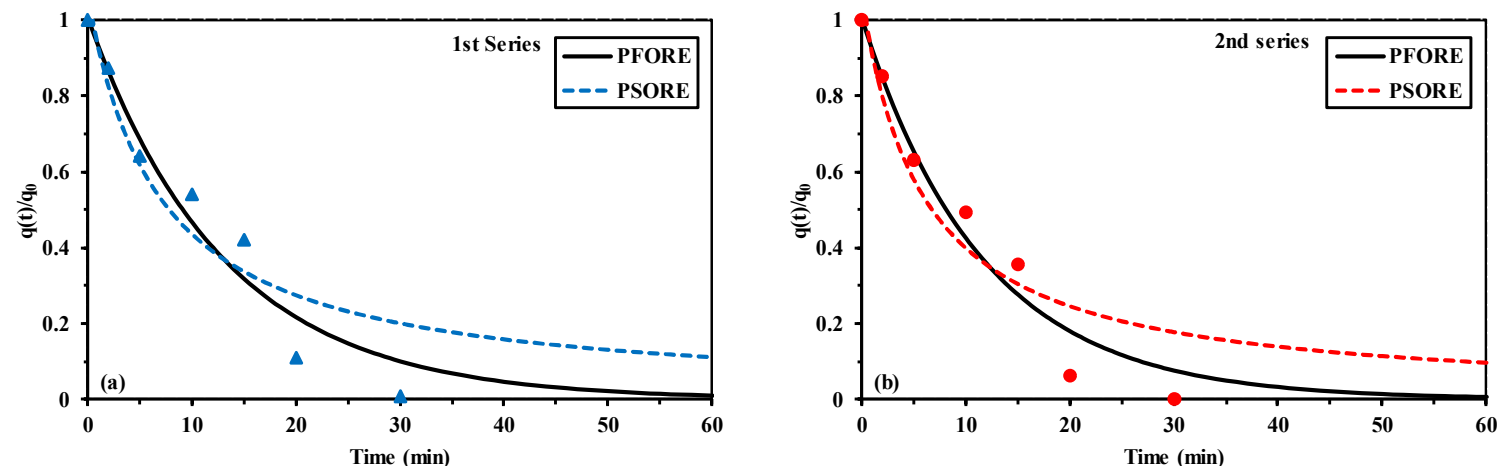

Figure 6. Desorption kinetics for U(VI) loaded on Q-APEI-Modeling with the PFORE and the PSORE for the 1st series (a) and the 2nd Series (b) (samples collected from uptake kinetics; eluent: $0.5 \mathrm{M}$ $\mathrm{NaCl} / 0.5 \mathrm{M} \mathrm{HCl}$; SD: $0.85 \mathrm{~g} \mathrm{~L}^{-1}$; agitation speed: $170 \mathrm{rpm}$; $\left.\mathrm{T}: 22 \pm 2{ }^{\circ} \mathrm{C}\right)$.

Table 4. Modeling of kinetic profiles for U(VI) desorption from loaded Q-APEI sorbent-PFORE and PSORE model [86].

\begin{tabular}{ccccccc}
\hline \multirow{2}{*}{ Sorbent } & Model & \multicolumn{2}{c}{ PFORE } & \multicolumn{3}{c}{ PSORE } \\
\cline { 2 - 7 } & Parameter & $\mathbf{k}_{\mathbf{D} \mathbf{1}}\left(\mathbf{m i n}^{-\mathbf{1}}\right)$ & $\mathbf{R}^{\mathbf{2}}$ & $\boldsymbol{\beta}_{\mathbf{2}}$ & $\mathbf{k}_{\mathbf{D} \mathbf{2}} \mathbf{( \mathbf { m i n } ^ { - 1 } )}$ & $\mathbf{R}^{\mathbf{2}}$ \\
\hline Q-APEI 1st Series & & 0.077 & 0.957 & 0.950 & 0.136 & 0.967 \\
Q-APEI 2nd series & & 0.086 & 0.917 & 0.950 & 0.157 & 0.914 \\
\hline
\end{tabular}

PFORE: $\frac{q(t)}{q_{0}}=e^{-k_{D 1} t}$ with: $\mathrm{k}_{\mathrm{D} 1}$ the apparent rate coefficient for desorption $\left(\mathrm{min}^{-1}\right)$ PSORE: $\frac{q(t)}{q_{0}}=\frac{1}{\beta_{2}+k_{\mathrm{D} 2} t}$ with: $\mathrm{k}_{\mathrm{D} 2}$ the apparent rate coefficient for desorption $\left(\mathrm{min}^{-1}\right)$ and $\beta_{2}$ (dimensionless) the constant for PSORE (in desorption).

Table 5. U(VI) desorption and sorbent recycling for Q-APEI.

\begin{tabular}{ccccc}
\hline \multirow{2}{*}{ Cycle } & \multicolumn{2}{c}{ Sorption Efficiency (\%) } & \multicolumn{2}{c}{ Desorption Efficiency (\%) } \\
\cline { 2 - 5 } & Average & S.D. & Average & S.D. \\
\hline 1 & 98.5 & 0.2 & 100.1 & 0.2 \\
2 & 98.0 & 0.1 & 99.9 & 0.9 \\
3 & 98.0 & 0.1 & 98.9 & 0.2 \\
4 & 97.9 & 0.0 & 99.4 & 1.0 \\
5 & 97.8 & 0.2 & 98.4 & 0.3 \\
\hline
\end{tabular}

(Experimental conditions: Sorption: $\mathrm{C}_{0}: 98 \mathrm{mg} \mathrm{U} \mathrm{L}^{-1}=0.413 \mathrm{mmol} \mathrm{U} \mathrm{L}^{-1}$; $\mathrm{pH}: 4 ; \mathrm{SD}: 1 \mathrm{~g} \mathrm{~L}^{-1}$; time: $24 \mathrm{~h} ; \mathrm{T}: 22 \pm 2{ }^{\circ} \mathrm{C}$; agitation speed: $170 \mathrm{rpm} /$ Desorption: eluent: $0.5 \mathrm{M} \mathrm{CaCl}_{2} / 0.5 \mathrm{M} \mathrm{HCl}$; SD: $2.5 \mathrm{~g} \mathrm{~L}^{-1}$; time: $2 \mathrm{~h} \mathrm{~T}$ : N; agitation speed: $170 \mathrm{rpm})$.

\subsection{Application to Uranium-Bearing Ores: Treatment of Acid Leachates}

The resin was tested for a very complex effluents obtained from acidic leaching of carbonaceous shale collected at the Allouga mining site.

\subsubsection{Acid Leaching of Ore and Pre-Treatment}

Table S9 reports the concentrations of the major elements in the acidic leachate (PLS). Copper and iron represent the most abundant metals: $34 \mathrm{~g} \mathrm{Cu} \mathrm{L}^{-1}$ and $6.5 \mathrm{~g} \mathrm{Fe} \mathrm{L}^{-1}$, respectively. Other valuable metals are also present at exploitable levels: $600 \mathrm{mg} \mathrm{U} \mathrm{L}^{-1}$ and $220 \mathrm{mg} \mathrm{REE} \mathrm{L}^{-1}$. The large excess of base metals limits the possibility to recover the valuable traces of $U$ and REEs. It is thus necessary pre-treating the PLS. Copper was separated by cementation and the analysis of the filtrate after cementation shows a low residual $\mathrm{Cu}$ concentration (close to $94 \mathrm{mg} \mathrm{Cu} \mathrm{L}^{-1}$ ): copper recovery reaches up to $99.6 \%$. Uranium loss reaches $25 \%$, while REEs remain almost unchanged (loss below $2.7 \%$ ). Obviously, the cementation using iron powder leads to an increase of iron concentration (up to $7.7 \mathrm{~g} \mathrm{Fe} \mathrm{L}^{-1}$ ). The semi-quantitative EDX analysis of the copper-cake shows the predominance of three 
elements: $\mathrm{Cu}(39.24 \%$, atomic fraction), S (38.38\%), and Fe (17.45\%) (Figure S6). The contamination of the copper-cake consists of $\mathrm{Si}(2.97 \%), \mathrm{P}(1.86 \%)$, and traces of $\mathrm{U}(0.1 \%)$.

Due to the large excess of iron in the treated PLS, a second pre-treatment was applied that consisted of the removal of Fe by precipitation. The $\mathrm{pH}$ was raised to 5 by $\mathrm{NaOH}$. The semi-quantitative EDX analysis of the iron precipitate shows that the precipitation is selective as $\mathrm{Fe}(\mathrm{OH})_{3}$; the presence of sulfur is due to highly sulfate medium from sulfuric acid pug leaching (Figure S7).

The filtrate was then treated with oxalic acid for selective precipitation of REEs oxalate. Table S9 reports the analysis of the solution after iron precipitation and REEs selective precipitation. These complementary treatments reduce the residual concentration of copper to $3 \mathrm{mg} \mathrm{Cu} \mathrm{L}^{-1}$, while the concentration of REEs decreases to $5.3 \mathrm{mg} \mathrm{L}^{-1}$ (97.5\% of REEs are removed after oxalate treatment). The yield of iron precipitation reaches 75\%: residual concentration remains close to $1925 \mathrm{mg} \mathrm{Fe} \mathrm{L}^{-1}$. After this series of treatments, uranium concentration reaches $350 \mathrm{mg} \mathrm{U} \mathrm{L}^{-1}$; the loss reaches $22.3 \%$ after iron and REEs precipitations. After the $\mathrm{Cu}$ cementation and the successive precipitation steps, the loss of uranium reaches $42 \%$.

\subsubsection{Metal Sorption from Leachates and Uranium Recovery}

Figure $\mathrm{S} 8$ shows the kinetic profiles for the sorption of $\mathrm{U}(\mathrm{VI})$ at $\mathrm{pH}_{0} 2$ and 4 ( $\mathrm{pH}_{\mathrm{eq}}: 2.98$ and 3.81, respectively). The kinetics are much slower with these complex solutions than with synthetic solutions: while less than $1 \mathrm{~h}$ was sufficient for reaching the equilibrium, with pre-treated PLS, a contact time of $24 \mathrm{~h}$ is necessary. As expected, the sorption efficiency is substantially enhanced at $\mathrm{pH} 4$ ( $58 \%$ instead of $23 \%$ at $\mathrm{pH}$ 2). The sorption capacity reaches $0.21 \mathrm{mmol} \mathrm{U} \mathrm{g}^{-1}$ (compared with $0.84 \mathrm{mmol} \mathrm{U} \mathrm{g}^{-1}$ ).

Figure $\mathrm{S} 9$ compares the distribution ratios $\left(\mathrm{D}, \mathrm{L} \mathrm{g}^{-1}\right)$ for $\mathrm{Cu}, \mathrm{Fe}$, and $\mathrm{U}$, for the two solutions. The values of $\mathrm{D}$ are very low for $\mathrm{Cu}$ and $\mathrm{Fe}$ (systematically below $0.01 \mathrm{~L} \mathrm{~g}^{-1}$ ), while for $\mathrm{U}$ the $\mathrm{D}$ value ranges between 0.07 and $0.35 \mathrm{~L} \mathrm{~g}^{-1}$ (from $\mathrm{pH} 2$ to $\mathrm{pH}$ 4). The relevant sorption capacities show negligible sorption of copper (very weak initial concentration) and comparable sorption capacities for iron (in very large excess) and uranium. Despite the 34 -fold excess of iron compared with uranium in the pre-treated PLS, the sorption of uranium reaches very high accumulation. Though the sorption is not selective, the sorption on Q-APEI allows enriching preferentially the resin with uranium. This is confirmed by the determination of the selectivity coefficients $\left(\mathrm{SC}_{\mathrm{U} / \text { metal }}: \mathrm{D}_{\mathrm{U}} / \mathrm{D}_{\text {metal }}\right)$ (Figure $\mathrm{S} 10$ ). Despite the large excess of iron, the $\mathrm{SC}_{\mathrm{U} / \mathrm{Fe}}$ is independent of the $\mathrm{pH}$ and close to 40 . Q-APEI is very efficient for $U$ sorption in complex solutions. The sorbent cannot separate $U$ from iron but the strong efficiency of the sorbent for uranium explains the high levels of accumulation of the metal on the sorbent.

The metals bound onto the sorbent (loaded at $\mathrm{pH} 2$ and 4) are eluted using $\mathrm{HCl}$ solution. The eluates are treated by precipitation using $\mathrm{NaOH}$ solution ( $\mathrm{pH}$ controlled to 9). The yellow cake (probably sodium diuranate, $\mathrm{Na}_{2} \mathrm{U}_{2} \mathrm{O}_{7}$ is collected by filtration, after washing several times with water for removing $\mathrm{NaCl}$, after drying, it was semi-quantitatively analyzed by EDX. Figure S11 shows that the precipitate obtained from sorbent loaded at $\mathrm{pH} 2$ contains a wide range of metals and elements (including iron, phosphorus, sodium, aluminum, calcium, silica, and chloride) with relatively low $\mathrm{U}$ atomic fraction (i.e., 8.78\%). On the opposite hand, the sorption at $\mathrm{pH} 4$ being more selective for $\mathrm{U}$, logically the relevant eluate contains a much higher fraction of U (AF: $55.34 \%$ and weight fraction: $51.6 \%$ ) and the impurities represent less than $8.3 \%(\mathrm{AF})$ and $3.3 \%$ (weight fraction).

\section{Conclusions}

In order to increase the sorption of uranyl ion, a new generation of composites made by the interaction of alginate (from algal biomass) and polyethylenimine (ionotropically gelled with $\mathrm{CaCl}_{2}$ and cross-linked with glutaraldehyde, respectively) is successfully quaternized by reaction with glycidyltrimethylammonium chloride. The quaternization shifts the $\mathrm{pH}_{\mathrm{PZC}}$ of the sorbent by $1.7 \mathrm{pH}$ units: the sorbent is fully protonated on the whole range of $\mathrm{pH}$ used for U(VI) sorption (below precipitation). The increased density of positively-charged sites enhances uranyl sorption that can 
reach $0.85 \mathrm{mmol} \mathrm{U} \mathrm{g}^{-1}$ at the optimum $\mathrm{pH}$ (i.e., $\mathrm{pH}$ 4). Sorption occurs by a combination of mechanisms, whose relative contributions depend on the $\mathrm{pH}$ and metal speciation, including: chelation of positively species on amine groups, binding of anionic species on protonated amine and quaternary ammonium reactive groups, binding on hydroxyl and carboxylate groups. The binding of sulfate anions may introduce some competition effects (the binding of sulfate anions is clearly identified by different techniques). These interactions are identified through FTIR and XPS analyses. Sorption is a relatively fast phenomenon: $40 \mathrm{~min}$ are sufficient for reaching equilibrium. The kinetic profiles are best fitted by the pseudo-first order rate equation (PFORE) while sorption isotherms are described by the Langmuir equation. Uranyl desorption is successfully operated using acidic $\mathrm{NaCl}$ solutions $(0.5 \mathrm{M} \mathrm{NaCl} / 0.5 \mathrm{M}$ $\mathrm{HCl}$ ): desorption kinetics (also fitted by the PFORE) is even faster than the sorption kinetics. The conditions for metal desorption are highly efficient (yield close to 100\%) and the sorbent can be re-used for a minimum of five cycles with negligible loss in efficiencies for both sorption and desorption; this is confirmed by the stability of FTIR spectra after five operating cycles. Acidic leachates of polymetallic carbonaceous shale are pre-treated for separating copper (by cementation) and rare earth elements (by oxalic acid precipitation). Though a precipitation step (adjusting the $\mathrm{pH}$ to 5) allows removal of an important fraction of iron, the residual concentration of Fe remains about 34-fold higher than $\mathrm{U}(\mathrm{VI})$ concentration. Despite this large excess, the sorbent can readily adsorb U(VI) and a yellow cake (sodium diuranate) is obtained after precipitation of the eluate. The grade of impurities in the yellow cake is much lower for sorbent processed at $\mathrm{pH} 4$.

Conventional resins are usually applied in dynamic systems using fixed-bed reactors. Therefore, complementary work would be necessary to evaluate the behavior of Q-APEI beads in columns and more specifically to compare the sorption capacities obtained at saturation of the bed with the sorption capacities reported in batch systems. The packing of Q-APEI beads in high column reactor is expected to produce important mechanical constraints. Therefore, it would be also useful evaluating the physical stability of the material under compression, especially along successive cycles of desorption and desorption.

\section{Materials and Methods}

\subsection{Materials}

Algal biomass (Laminaria digitata) was provided by Setalg (Pleubian, France). The biomass was grinded and the fraction below $250 \mu \mathrm{m}$ was collected for processing the synthesis of the sorbent. Alginate (Manugel GMB) was supplied by FMC (Landerneau, France; now JRS Rettenmaier). This alginate has the following specifications: water content $16.3 \%$ (by TGA), MW 446,000 $\mathrm{g} \mathrm{mol}^{-1}$ (viscosimetric measurements and Mark Houwink Sakurada equation) and G/M ratio 0.19/0.81 (by ${ }^{1} \mathrm{H}$ NMR analysis). Polyethylenimine (branched PEI, 50\% w/w) was purchased from Sigma-Aldrich (Taufkirchen, Germany). Ethylene glycol diglycidyl ether, glycidyltrimethylammonium chloride $(\geq 95 \%)$ and dimethylformamide (DMF) were purchased from Shanghai Makclin Biochemical Co., Ltd. (Shanghai, China). $\mathrm{Na}_{2} \mathrm{CO}_{3}$ and $\mathrm{CaCl}_{2}$ were obtained from Chem-Lab NV (Zedelgem, Belgium). Uranyl sulfate (single-metal experiments) was supplied by Polysciences Europe $\mathrm{GmbH}$ (Hirschberg an der Bergstraße, Germany).

\subsection{Sorbent Synthesis}

The first step in the process consists of the particle extraction of alginate contained in algal biomass by a thermal alkaline extraction: algal biomass $(9.375 \mathrm{~g})$ was mixed for $24 \mathrm{~h}$ at T: $50{ }^{\circ} \mathrm{C}$ in $375 \mathrm{~mL}$ of sodium carbonate $(1 \% w / w)$. Preliminary experiments showed that depending on the mode of functionalization, the addition of a small amount of alginate contributes to reinforce the stability of the sorbent. After alkaline thermal extraction, the suspension was mixed with $125 \mathrm{~mL}$ of alginate solution $(4 \% w / w)$, completed with $5 \mathrm{~mL}$ of Polyethylenimine. After homogenization of the mixture, the suspension was dropped through a thin nozzle into an ionotropic gelation bath, constituted of $1 \mathrm{~L}$ of 
$\mathrm{CaCl}_{2}$ solution $(1 \% w / w)$ containing $5 \mathrm{~mL}$ of glutaraldehyde (GA, $\left.50 \% w / w\right)$. The alginate fraction (from algal biomass and pure biopolymer) was ionotropically gelled with calcium while glutaraldehyde reacts with amine groups on PEI to form a supplementary crosslinking network. The beads remained overnight in the solution before being thoroughly washed with demineralized water. The beads (APEI) were finally freeze-dried $\left(-52^{\circ} \mathrm{C}, 0.1 \mathrm{mbar}\right.$, for two days).

Prior to functionalization of APEI beads, the stability of the beads was chemically strengthened by complementary crosslinking using poly(ethyleneglycol) diglycidyl ether $(3 \mathrm{~mL}$ dissolved into $90 \mathrm{~mL}$ of isopropanol): $5 \mathrm{~g}$ of APEI beads were mixed under reflux with the cross-linking solution. Cross-linked beads were finally recovered by filtration and successively rinsed with demineralized water and methanol, before being vacuum dried at $50{ }^{\circ} \mathrm{C}$ overnight.

Five $\mathrm{g}$ of cross-linked beads were dispersed into $140 \mathrm{~mL}$ DMF: $\mathrm{H}_{2} \mathrm{O}(1: 1, v / v)$ mixture in a three-necked reactor. Glycidyltrimethylammonium chloride $(10 \mathrm{~g})$ was added to the suspension under reflux (T: $73^{\circ} \mathrm{C}$ for $24 \mathrm{~h}$ ) with gentle agitation. Produced quaternized beads (Q-APEI) were washed three times with hot water and methanol before being vacuum dried overnight at $50^{\circ} \mathrm{C}$. Scheme 2 shows the chemical structure of the sorbent, while Scheme S1 (see Supplementary Information) summarizes the main steps of the functionalization of APEI beads.

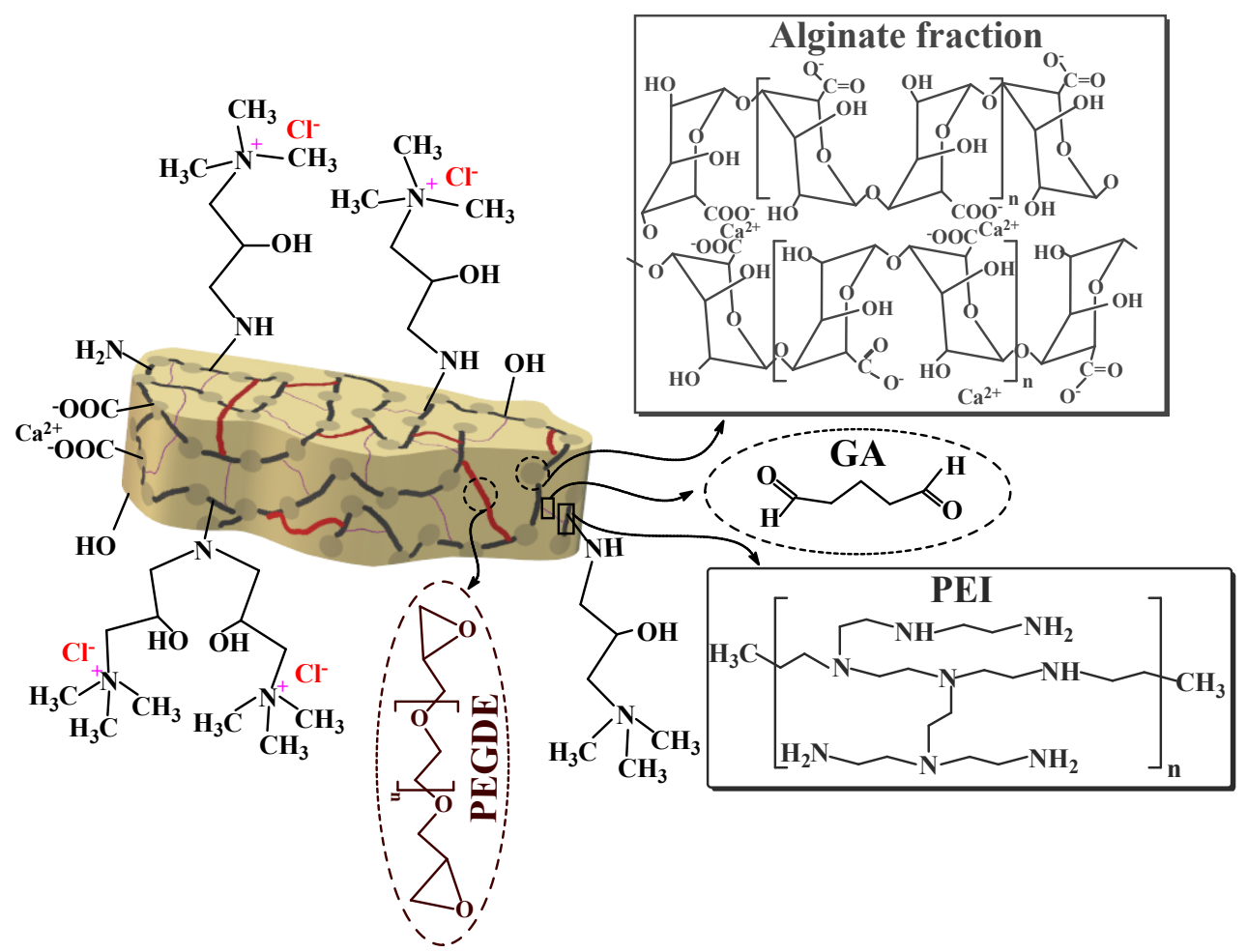

Scheme 2. Structure of the sorbent.

\subsection{Material Characterization}

Conventional analytical methods were used for characterizing the materials (APEI and Q-APEI) for elemental analysis, textural properties (BET analysis), thermogravimetric analysis (TGA analysis), and morphological observation (SEM) and SEM-EDX, (XL30-ESEM, Philips, FEI, Thermo Fisher Scientific, Hillsboro, OR, USA). These physical and chemical properties have been previously reported [41]. Briefly, Q-APEI is characterized by a specific surface area close to $34 \mathrm{~m}^{2} \mathrm{~g}^{-1}$, with a porous volume of $0.181 \mathrm{~cm}^{3} \mathrm{~g}^{-1}$ and an average pore size of $183-230 \mathrm{~nm}$. The nitrogen content in Q-APEI represents around $8.57 \% w / w$, or $6.12 \mathrm{mmol} \mathrm{N} \mathrm{g}{ }^{-1}$. The thermogravimetric analysis showed several steps of degradation corresponding to water desorption, degradation of amine compounds, depolymerization, 
and char degradation. The residual fraction does not exceed a few percent at $800^{\circ} \mathrm{C}$. The sorbent is roughly stable until temperature reaches around $230^{\circ} \mathrm{C}$.

FT-IR spectra were obtained using an IRTracer-100 FT-IR spectrometer (Shimadzu, Tokyo, Japan). All the samples were dried at $60^{\circ} \mathrm{C}$ before being analyzed. Samples were conditioned as KBr disk. XPS spectra were collected using an ESCALAB 250XI+ instrument (Thermo Fischer Scientific, Inc., Waltham, MA, USA) with monochromatic $\mathrm{X}$-ray Al $\mathrm{K} \alpha$ radiation $(1486.6 \mathrm{eV})$. The signals corresponding to $\mathrm{Ag}$ $3 \mathrm{~d}_{5 / 2}(\triangle \mathrm{BE}: 0.45 \mathrm{eV})$ and $\mathrm{C} 1 \mathrm{~s}(\triangle \mathrm{BE}: 0.82 \mathrm{eV})$ were used for calibrating the analytical procedure. The full-spectrum pass energy and narrow-spectrum pass energy were set at 50 and $20 \mathrm{eV}$, respectively. SEM (scanning electron microscopy) observations were performed on a Phenom ProX SEM, Thermo Fisher Scientific, Eindhoven, Netherlands) at an accelerating voltage of $15 \mathrm{kV}$. The chemical composition of the samples was characterized by energy dispersive $\mathrm{X}$-ray analysis (integrated to Phenom ProX SEM).

The $\mathrm{pH}$-drift method was used for the determination of $\mathrm{pH}_{\mathrm{PZC}}(\mathrm{pH}$ of zero charge) [87]. Two series of 0.1 and $1 \mathrm{M} \mathrm{NaCl}$ solutions were prepared (initial $\mathrm{pH}$ varying between 1 and 11) and mixed with the sorbent for $48 \mathrm{~h}$ (sorbent dosage: $2 \mathrm{~g} \mathrm{~L}^{-1}$ ). The equilibrium $\mathrm{pH}\left(\mathrm{pH}_{\mathrm{eq}}\right)$ was measured in the filtrate using a S220 Seven Compact $\mathrm{pH} /$ Ionometer (Mettler-Toledo Instruments, Shanghai, China). The $\mathrm{pH}_{\mathrm{PZC}}$ was defined by the $\mathrm{pH}$ value that corresponds to $\mathrm{pH}_{0}=\mathrm{pH}_{\mathrm{eq}}$.

\subsection{Sorption Studies}

\subsubsection{Sorption and Desorption Tests}

Sorption studies were carried out in the batch mode (temperature: $22 \pm 2{ }^{\circ} \mathrm{C}$; agitation speed: $170 \mathrm{rpm})$. A given amount of sorbent $(\mathrm{m}, \mathrm{g})$ was mixed with a fixed volume $(\mathrm{V}, \mathrm{L})$ of metal-containing solution $\left(\mathrm{C}_{0}, \mathrm{mmol} \mathrm{U} \mathrm{L}^{-1}\right)$ at fixed initial $\mathrm{pH}\left(\mathrm{pH}_{0}\right)$. Samples are collected and filtrated at fixed contact times for studying uptake kinetics; for equilibrium tests, the contact time was set to $48 \mathrm{~h}$. For sorption isotherms, the initial concentration was varied between 10 and $500 \mathrm{mg} \mathrm{U} \mathrm{L}^{-1}$ (i.e., $0.043-2.13 \mathrm{mmol} \mathrm{U} \mathrm{L}^{-1}$ ). The $\mathrm{pH}$ was not adjusted during sorption tests but the equilibrium $\mathrm{pH}$ was systematically monitored. Residual metal concentration $\left(\mathrm{C}_{\mathrm{eq}}, \mathrm{mmol} \mathrm{U} \mathrm{L}^{-1}\right)$ was determined by inductively-coupled plasma atomic emission spectrometry (ICP-AES, ICPS-7510, Shimadzu, Tokyo, Japan), after filtered on $1.2-\mu \mathrm{m}$ pore size filter membranes. The sorption efficiency was calculated as well as the sorption capacity $\left(\mathrm{q}_{\mathrm{eq}}, \mathrm{mmol} \mathrm{U} \mathrm{g}^{-1}\right)$ deduced from the mass balance equation: $\mathrm{q}_{\mathrm{eq}}=\left(\mathrm{C}_{0}-\mathrm{C}_{\mathrm{eq}}\right) \times \mathrm{V} / \mathrm{m}$. For experiments involving different metal ions, the same sorption procedure was adopted. The metal concentration was determined by UV-Visible spectroscopy (Shimadzu UV-160A, Tokyo, Japan) for U(VI) and REEs using 0.05\% w/w Arsenazo III colorimetric method at 655 and $654 \mathrm{~nm}$, respectively [88]. Zinc and copper ions were analyzed by atomic absorption spectrometry (Unicam 969, Thermo Electron Corporation).

An acidic $\mathrm{NaCl}$ solution $(0.5 \mathrm{M} \mathrm{NaCl} / 0.5 \mathrm{M} \mathrm{HCl})$ was used for processing desorption of uranyl from metal-loaded sorbent. For desorption kinetics, the beads loaded with uranyl from the study of uptake kinetics were used. The same batch procedure (as for sorption study) was used for testing the regeneration of the sorbent through a series of five cycles of sorption and desorption.

Details of experimental procedures are systematically reported in the caption of the figures (sorbent dosage, $\mathrm{SD}, \mathrm{g} \mathrm{L}^{-1}$; metal concentrations, $\mathrm{pH}_{0}$ and $\mathrm{pH}_{\mathrm{eq}}$, temperature, agitation time and agitation speed, etc.). Sorption tests are duplicated (Figures show this duplication comparing Series \#1 and Series \#2).

\subsubsection{Modeling}

Tables S1 and S2 (see Additional Material Section) report the conventional equations used for modeling uptake kinetics (pseudo-first and pseudo-second order rate equations, PFORE and PSORE; the Crank equation for simulating the resistance to intraparticle diffusion) and sorption isotherms (Langmuir, Freundlich, and Sips equations). The parameters of the models were obtained using non-linear regression analysis (facilities from Mathematica ${ }^{\circledR}$ software); the fit adjustment was measured 
calculating the determination coefficients (comparing experimental data and simulated data) and also comparing calculated and experimental sorption capacities (maximum sorption capacities for sorption isotherms and equilibrium sorption capacities for uptake kinetics).

\subsection{Processing of Uranium-Bearing Ore and Uranium Recovery}

Sorption tests on industrial effluents were carried out on the leachates of ore samples collected in the so-called Alloga locality (close to Abu Zeneima, in SW Sinai, Egypt). The ore is characterized as a polymetallic carbonaceous shale. Figure S12 shows the geological map corresponding to Abu Zeneima area.

The mineralogical analysis showed the presence of several economic minerals including monazite (phosphate of rare earth elements), sklodowskite $\left(\mathrm{Mg}\left(\mathrm{UO}_{2}\right)_{2}\left(\mathrm{HSiO}_{4}\right)_{2} \cdot 5 \mathrm{H}_{2} \mathrm{O}\right)$, azurite $\left(\mathrm{Cu}_{3}\left(\mathrm{CO}_{3}\right)_{2}(\mathrm{OH})_{2}\right)$, malachite $\left(\mathrm{Cu}_{2} \mathrm{CO}_{3}(\mathrm{OH})_{2}\right)$, atacamite $\left(\mathrm{Cu}_{2} \mathrm{Cl}(\mathrm{OH})_{3}\right)$, carrollite $\left(\mathrm{Cu}_{2} \mathrm{Cl}(\mathrm{OH})_{3}\right)$, chalcopyrite $\left(\mathrm{CuFeS}_{2}\right)$, siegenite $\left((\mathrm{Ni}, \mathrm{Co})_{3} \mathrm{~S}_{4}\right)$, polydymite $\left(\mathrm{Ni}_{3} \mathrm{~S}_{4}\right)$, violarite $\left(\mathrm{Fe}^{2+} \mathrm{Ni}_{2}{ }^{3+} \mathrm{S}_{4}\right)$, and zircon $\left(\mathrm{ZrSiO}_{4}\right)$.

Major oxide and trace elements were analyzed by conventional methods (including fusion, mineralization and metal analysis by atomic absorption spectrometry [6]). A wide range of valuable metals are present in the polymetallic ore, including $\mathrm{Cu}(2.4 \% w / w)$, REEs $(0.22 \%), \mathrm{U}(0.62 \%), \mathrm{V}(0.13 \%)$, $\mathrm{Ni}(0.25 \%)$, and $\mathrm{Co}(0.11 \%)$ in addition to a remarkable amount of $\operatorname{Zr}(0.025 \%)$ (from [89]).

A series of leaching studies were carried out for the optimization of sulfuric acid leaching (stirred reactor), alkali agitation leaching, and pug leaching method. The pug leaching process achieved the highest efficiency in metal release under the following conditions: 1.35 ton of $\mathrm{H}_{2} \mathrm{SO}_{4}$ was stirred with 1 ton of ore at $\mathrm{T}$ : $110^{\circ} \mathrm{C}$ for $2 \mathrm{~h}$. leachates contained: $6.5 \mathrm{~g} \mathrm{Fe} \mathrm{L}^{-1}, 3.4 \mathrm{~g} \mathrm{Cu} \mathrm{L}^{-1}, 0.22 \mathrm{~g} \mathrm{REEs} \mathrm{L}-1$, $0.6 \mathrm{~g} \mathrm{U} \mathrm{L}^{-1}$, and $0.19 \mathrm{~g} \mathrm{~V} \mathrm{~L}^{-1}$.

The pregnant leach solution (PLS) was first treated by cementation (using Fe powder, $0.3 \mathrm{~g}$ of iron for $100 \mathrm{~mL}$ of PLS) to precipitate copper as $\mathrm{Cu}$ metal. The reaction was carried out at $\mathrm{pH} 0.7$, for $30 \mathrm{~min}$ at $\mathrm{T}: 70{ }^{\circ} \mathrm{C}$.

The $\mathrm{Cu}$-depleted leachate was then treated with oxalic acid for selectively separating rare earths from uranium in the liquor. A $10 \% w / w$ oxalic acid solution was added to the liquor at $\mathrm{pH} 1.1$, at $\mathrm{T}$ : $22{ }^{\circ} \mathrm{C}$, under agitation for $45 \mathrm{~min}$. Turbid RE oxalate suspension was recovered by filtration. Prior treating the residual solution by sorption on Q-APEI, the $\mathrm{pH}$ was controlled to 5 to remove the major part of iron by precipitation. The filtrate was separated into two stock solutions that were controlled at pH 2 and $\mathrm{pH} 4$, respectively.

Sorption tests on these solutions were carried out in stirred tank reactor by contact of $200 \mathrm{mg}$ of sorbent with $50 \mathrm{~mL}$ of pre-treated leachates. Samples were collected at fixed contact times (i.e., 1, 2, $4,10,20$, and $24 \mathrm{~h}$ ) for quantification of residual concentrations ( $\mathrm{U}, \mathrm{Cu}$, and $\mathrm{Fe}$ ) in filtrated solutions. At the end of sorption tests, uranium was desorbed from loaded resins using $0.5 \mathrm{M} \mathrm{HCl}$ solution (V: $30 \mathrm{~mL}$ ) under agitation for $30 \mathrm{~min}$. The yellow cake was obtained by precipitation of the eluate with $1 \mathrm{M} \mathrm{NaOH}$ solution, adjusting the $\mathrm{pH}$ to 9. The semi-quantitative composition of the yellow cake was determined by EDX analysis.

Supplementary Materials: The following are available online at http://www.mdpi.com/2310-2861/6/2/12/s1, Scheme S1: Main steps of the procedure of quaternization of APEI beads. Table S1: FTIR assignments peaks and corresponding wavenumbers $\left(\mathrm{cm}^{-1}\right)$ of APEI, Q-APEI, Q-APEI+U, and Q-APEI after desorption and Q-APEI after 5 cycles of sorption/desorption. Table S2: H-Res. XPS peaks of C 1s, O 1s, N 1s, Ca 2p and S 2p for APEI and Q-APEI sorbent. Table S3: Assignments, Binding energies (BEs), Full width at half-maximum (FWHM) and Atomic Fractions (AF) (\%) of APEI, and Q-APEI sorbents. Table S4: H-RES. XPS characterization of Q-APEI after loading with uranyl ions. Table S5: Assignments, Binding energies (BEs), Full width at half-maximum (FWHM) and Atomic Fractions (AF) (\%) of APEI, and Q-APEI sorbents. Table S6: SEM-EDX analysis of Q-APEI after U(VI) sorption at different $\mathrm{pH}$ values. Table S7: Uptake kinetics modeling-PFORE (pseudo-first order rate equation), PSORE (pseudo-second order rate equation), and RIDE (resistance to intraparticle diffusion equation-Crank equation). Table S8: Sorption isotherm modeling [90,91]. Table S9: Pre-treatment of PLS (Abu Zeneima ore): initial concentrations of major elements and residual concentrations after $\mathrm{Cu}$ cementation, and after separation of REEs (by oxalic precipitation) and iron abatement ( $\mathrm{pH}$ control). Table S10: Semi-quantitative EDX analysis of loaded sorbent (pre-treated leachate at $\mathrm{pH} 2$ and 4). Figure S1: Determination of the $\mathrm{pH}_{\mathrm{PZC}}$ of APEI and Q-APEI sorbents by the $\mathrm{pH}$-drift method (Sorbent dosage, SD: $2 \mathrm{~g} \mathrm{~L}^{-1}$; contact time: $48 \mathrm{~h}$; agitation speed: $170 \mathrm{rpm}$; 
background salt $\mathrm{NaCl} 1 \mathrm{M}$ (dashed lines) and $0.1 \mathrm{M}$ (solid lines); $\mathrm{T}: 22 \pm 2{ }^{\circ} \mathrm{C}$ ). Figure S2: Effect of equilibrium $\mathrm{pH}$ on the distribution ratio of $\mathrm{U}(\mathrm{VI})\left(\log _{10} \mathrm{plot}\right)$ for APEI and Q-APEI sorbents (Sorbent dosage, SD: $0.333 \mathrm{~g} \mathrm{~L}^{-1}$; contact time: $48 \mathrm{~h}$; agitation speed: $170 \mathrm{rpm}$; T: $22 \pm 2{ }^{\circ} \mathrm{C}$ ). Figure S3: U(VI) speciation in function of $\mathrm{pH}(\mathrm{a})$ and total metal concentration at $\mathrm{pH} 4$ (b) (following the experimental conditions relevant to $\mathrm{pH}$ study and sorption isotherms, respectively; calculations performed using Visual Minteq, [92]). Figure S4: Variation of $\mathrm{pH}$ during $\mathrm{U}(\mathrm{VI})$ sorption using APEI and Q-APEI sorbents (Sorbent dosage, SD: $0.333 \mathrm{~g} \mathrm{~L}^{-1}$; contact time: $48 \mathrm{~h}$; agitation speed: $170 \mathrm{rpm} ; \mathrm{T}: 22 \pm 2{ }^{\circ} \mathrm{C}$ ). Figure S5: U(VI) uptake kinetics using Q-APEI sorbent-Modeling with the PSORE (a) and the RIDE (b) (SD: $0.3 \mathrm{~g} \mathrm{~L}^{-1} ; \mathrm{pH}_{0}: 4 ; \mathrm{pH}_{\mathrm{eq}}$ : 3.79-3.71; $\mathrm{C}_{0}: 0.214 \mathrm{mmol} \mathrm{U} \mathrm{L}^{-1}$ and $0.249 \mathrm{mmol} \mathrm{U} \mathrm{L}^{-1}$ for 1 st and 2nd series, respectively; agitation speed: $170 \mathrm{rpm}$; T: $22 \pm 2{ }^{\circ} \mathrm{C}$ ). Figure S6: Semi-quantitative EDX analysis of copper-cake collected after cementation. Figure S7: Semi-quantitative EDX analysis of iron-cake after $\mathrm{pH}$ control at $\mathrm{pH}$ 5. Figure S8: Effect of time on uranium sorption from multi-component solutions $\left(\mathrm{C}_{0}\right.$ : $350-346 \mathrm{mg} \mathrm{U} \mathrm{L}^{-1}=$ 1.47-1.45 mmol U L ${ }^{-1}$; T: $22 \pm 2{ }^{\circ} \mathrm{C}$; SD: $0.125 \mathrm{~g} \mathrm{~L}^{-1}$; agitation speed: $170 \mathrm{rpm}$ ). Figure S9: Distribution ratios of $\mathrm{Cu}, \mathrm{Fe}$, and $\mathrm{U}$ after sorption on Q-APEI at $\mathrm{pH}_{\mathrm{eq}}$ : 2.98 and $3.81\left(\mathrm{pH}_{0}: 2\right.$ and 4, respectively) from pre-treated PLS (inserted numbers represent the relevant sorption capacities at equilibrium, $\mu \mathrm{mol} \mathrm{g}^{-1}$ ). Figure S10: Selectively coefficients $\mathrm{SC}_{\mathrm{U} / \mathrm{Cu}}$ and $\mathrm{SC}_{\mathrm{U} / \mathrm{Fe}}$ for metal sorption from pre-treated PLS $\left(\mathrm{C}_{0}: 3 \mathrm{mg} \mathrm{Cu} \mathrm{L}{ }^{-1}=0.047 \mathrm{mmol} \mathrm{Cu} \mathrm{L}^{-1}\right.$, $1925 \mathrm{mg} \mathrm{Fe} \mathrm{L}^{-1}=34.47 \mathrm{mmol} \mathrm{Fe} \mathrm{L}^{-1}, 350-346 \mathrm{mg} \mathrm{U} \mathrm{L}^{-1}=1.47-1.45 \mathrm{mmol} \mathrm{U} \mathrm{L}{ }^{-1}$; SD: $0.125 \mathrm{~g} \mathrm{~L}^{-1}$; agitation speed: $170 \mathrm{rpm}$; agitation time: $24 \mathrm{~h}$ ). Figure S11. Semi-quantitative analysis of the yellow cake produced from the eluates of sorbent after U-loading from ore leachates at $\mathrm{pH} 2$ and $\mathrm{pH}$ 4. Figure S12: Alloga locality of Abu Zienema area, South Western Sinai, Egypt.

Author Contributions: Conceptualization and methodology, E.G. and M.F.H.; validation and preparation of leachate solution, A.E.M.; software, Y.W. and M.F.H.; formal analysis, E.G.; investigation, T.V., M.F.H. and A.E.M.; resources, Y.W. and E.G.; data curation, Y.W.; writing-original draft preparation, E.G. and M.F.H.; writing-review and editing, E.G. and M.F.H.; visualization, E.G., Y.W. and M.F.H.; project administration, Y.W. and E.G.; funding acquisition, Y.W. All authors have read and agreed to the published version of the manuscript.

Funding: Y.W. thanks the support of NSFC projects (National Natural Science Foundation of China, No.11675102, 11975082, and U1967218).

Acknowledgments: E.G.: T.V., M.F.H., and A.E.M. acknowledge "Institut Français d'Egypte” (“Ministère des Affaires Etrangères") and "Ministère de l'Enseignement Supérieur et de la Recherche" for supporting the collaboration between IMT-Mines Ales and Nuclear Materials Authority. Shengye Wang and Yayuan MO (PCH, IMT-Mines Ales) are acknowledged for their support in preparing APEI beads.

Conflicts of Interest: The authors declare no conflict of interest.

\section{References}

1. Orabi, A.H.; El-Sheikh, E.M.; Saleh, W.H.; El-Saied, F.A.; El-Gendy, H.S.; Ismaiel, D.A. Recovery of uranium and copper from mineralized dolostone, Gabal Allouga, Southwestern Sinai, Egypt. J. Radiat. Res. Appl. Sci. 2019, 12, 10-23. [CrossRef]

2. Kim, J.S.; Chung, K.W.; Lee, H.I.; Yoon, H.-S.; Kumar, J.R. Leaching behavior of uranium and vanadium using strong sulfuric acid from Korean black shale ore. J. Radioanal. Nucl. Chem. 2014, 299, 81-87. [CrossRef]

3. Aal, M.M.A. Preparation of a uranium leach liquor from a refractory ore using nitric acid solution. Int. J. Environ. Anal. Chem. 2019, 1-24. [CrossRef]

4. Szolucha, M.M.; Chmielewski, A.G. A comparison of uranium recovery from low-grade ore by bioleaching and acid leaching. Physicochem. Probl. Miner. Process. 2017, 53, 136-149.

5. Xu, L.; Yang, H.; Liu, Y.; Zhou, Y. Uranium leaching using citric acid and oxalic acid. J. Radioanal. Nucl. Chem. 2019, 321, 815-822. [CrossRef]

6. Hamza, M.F.; El-Aassy, I.E.; Guibal, E. Integrated treatment of tailing material for the selective recovery of uranium, rare earth elements and heavy metals. Miner. Eng. 2019, 133, 138-148. [CrossRef]

7. Avelar, E.C.; Alvarenga, C.L.G.; Resende, G.P.S.; Morais, C.A.; Mansur, M.B. Modeling of the solvent extraction equilibrium of uranium(VI) sulfate with Alamine 336. Braz. J. Chem. Eng. 2017, 34, 355-362. [CrossRef]

8. Kiegiel, K.; Abramowska, A.; Bieluszka, P.; Zakrzewska-Koltuniewicz, G.; Wolkowicz, S. Solvent extraction of uranium from leach solutions obtained in processing of Polish low-grade ores. J. Radioanal. Nucl. Chem. 2017, 311, 589-598. [CrossRef]

9. Zhu, Z.; Pranolo, Y.; Cheng, C.Y. Uranium recovery from strong acidic solutions by solvent extraction with Cyanex 923 and a modifier. Miner. Eng. 2016, 89, 77-83. [CrossRef]

10. Merdivan, M.; Duz, M.Z.; Hamamci, C. Sorption behaviour of uranium(VI) with N,N-dibutyl-N '-benzoylthiourea Impregnated in Amberlite XAD-16. Talanta 2001, 55, 639-645. [CrossRef] 
11. Rahmani-Sani, A.; Hosseini-Bandegharaei, A.; Hosseini, S.H.; Kharghani, K.; Zarei, H.; Rastegar, A. Kinetic, equilibrium and thermodynamic studies on sorption of uranium and thorium from aqueous solutions by a selective impregnated resin containing carminic acid. J. Hazard. Mater. 2015, 286, 152-163. [CrossRef] [PubMed]

12. Singh, K.K.; Pathak, S.K.; Kumar, M.; Mahtele, A.K.; Tripathi, S.C.; Bajaj, P.N. Study of uranium sorption using D2EHPA-impregnated polymeric beads. J. Appl. Polym. Sci. 2013, 130, 3355-3364. [CrossRef]

13. Erkaya, I.A.; Arica, M.Y.; Akbulut, A.; Bayramoglu, G. Biosorption of uranium(VI) by free and entrapped Chlamydomonas reinhardtii: Kinetic, equilibrium and thermodynamic studies. J. Radioanal. Nucl. Chem. 2014, 299, 1993-2003. [CrossRef]

14. Lu, X.; Zhou, X.-J.; Wang, T.-S. Mechanism of uranium(VI) uptake by Saccharomyces cerevisiae under environmentally relevant conditions: Batch, HRTEM, and FTIR studies. J. Hazard. Mater. 2013, 262, 297-303. [CrossRef]

15. Prodromou, M.; Pashalidis, I. Uranium adsorption by non-treated and chemically modified cactus fibres in aqueous solutions. J. Radioanal. Nucl. Chem. 2013, 298, 1587-1595. [CrossRef]

16. Safonov, A.; Tregubova, V.; Ilin, V.; Boldyrev, K.; Zinicovscaia, I.; Frontasyeva, M.; Khijniak, T. Comparative study of lanthanum, vanadium, and uranium bioremoval using different types of microorganisms. Water Air Soil Pollut. 2018, 229, 82. [CrossRef]

17. Ang, K.L.; Li, D.; Nikoloski, A.N. The effectiveness of ion exchange resins in separating uranium and thorium from rare earth elements in acidic aqueous sulfate media. Part 2. Chelating resins. Miner. Eng. 2018, 123, 8-15. [CrossRef]

18. Cao, Q.; Liu, Y.; Kong, X.; Zhou, L.; Guo, H. Synthesis of phosphorus-modified poly(styrene-co-divinylbenzene) chelating resin and its adsorption properties of uranium(VI). J. Radioanal. Nucl. Chem. 2013, 298, 1137-1147. [CrossRef]

19. Kabay, N.; Demircioglu, M.; Yayli, S.; Gunay, E.; Yuksel, M.; Saglam, M.; Streat, M. Recovery of uranium from phosphoric acid solutions using chelating ion-exchange resins. Ind. Eng. Chem. Res. 1998, 37, 1983-1990. [CrossRef]

20. Liu, Z.; Liu, D.; Cai, Z.; Wang, Y.; Zhou, L. Synthesis of new type dipropyl imide chelating resin and its potential for uranium(VI) adsorption. J. Radioanal. Nucl. Chem. 2018, 318, 1219-1227. [CrossRef]

21. Amphlett, J.T.M.; Ogden, M.D.; Foster, R.I.; Syna, N.; Soldenhoff, K.H.; Sharrad, C.A. The effect of contaminants on the application of polyamine functionalised ion exchange resins for uranium extraction from sulfate based mining process waters. Chem. Eng. J. 2018, 354, 633-640. [CrossRef]

22. Amphlett, J.T.M.; Sharrad, C.A.; Foster, R.I.; Ogden, M.D. Ethylenediamine-funtionalized ion exchange resin for uranium recovery from acidic mixed sulphate-chloride media: Initial column loading studies. J. South Afr. Inst. Min. Metall. 2018, 118, 1251-1257. [CrossRef]

23. Dlamini, T.C.; Tshivhase, V.M.; Maleka, P.; Penabei, S.; Mashaba, M. The effect of uranium speciation on the removal of gross alpha activity from acid mine drainage using anion exchange resin. J. Radioanal. Nucl. Chem. 2019, 319, 357-363. [CrossRef]

24. Foster, R.I.; Amphlett, J.T.M.; Kim, K.-W.; Kerry, T.; Lee, K.; Sharrad, C.A. SOHIO process legacy waste treatment: Uranium recovery using ion exchange. J. Ind. Eng. Chem. 2020, 81, 144-152. [CrossRef]

25. Karan, R.; Rajan, K.C.; Sreenivas, T. Studies on lowering of uranium from mine water by static bed ion exchange process. Sep. Sci. Technol. 2019, 54, 1607-1619. [CrossRef]

26. Wen, Z.; Huang, K.; Niu, Y.; Yao, Y.; Wang, S.; Cao, Z.; Zhong, H. Kinetic study of ultrasonic-assisted uranium adsorption by anion exchange resin. Colloids Surf. A 2020, 585, 124021. [CrossRef]

27. El-Magied, M.O.A.; Dhmees, A.S.; Abd El-Hamid, A.A.M.; Eldesouky, E.M. Uranium extraction by sulfonated mesoporous silica derived from blast furnace slag. J. Nucl. Mater. 2018, 509, 295-304. [CrossRef]

28. Guo, X.; Feng, Y.; Ma, L.; Gao, D.; Jing, J.; Yu, J.; Sun, H.; Gong, H.; Zhang, Y. Phosphoryl functionalized mesoporous silica for uranium adsorption. Appl. Surf. Sci. 2017, 402, 53-60.

29. Kouraim, M.N.; Hagag, M.S.; Ali, A.H. Sorption of uranium from radioactive wastes by silicate-neutralised polyacrylic. Int. J. Environ. Anal. Chem. 2019, 1-16. [CrossRef]

30. Liao, R.; Shi, Z.; Hou, Y.; Zhang, K.; Zhang, J.; Wang, X.; Cheng, K.; Yang, L. Uranium sorption onto mullite: Characteristics of isotherms, kinetics and thermodynamics. J. Earth Syst. Sci. 2019, 128, 176. 
31. Xiao, J.; Jing, Y.; Wang, X.Q.; Yao, Y.; Jia, Y.Z. Preconcentration of uranium(VI) from aqueous solution by amidoxime-functionalized microspheres silica material: Kinetics, isotherm and mechanism study. Chemistryselect 2018, 3, 12346-12356. [CrossRef]

32. Xie, Y.; Chen, C.L.; Ren, X.M.; Wang, X.X.; Wang, H.Y.; Wang, X.K. Emerging natural and tailored materials for uranium-contaminated water treatment and environmental remediation. Prog. Mater. Sci. 2019, 103, 180-234. [CrossRef]

33. Yang, P.P.; Liu, Q.; Liu, J.Y.; Chen, R.R.; Li, R.M.; Bai, X.F.; Wang, J. Highly efficient immobilization of uranium(VI) from aqueous solution by phosphonate-functionalized dendritic fibrous nanosilica (DFNS). J. Hazard. Mater. 2019, 363, 248-257. [CrossRef] [PubMed]

34. Yang, Z.; Chen, G.; Weng, H.; Shen, W.; Huang, Z.; Lin, M. Efficient and selective separation of U(VI) and Th(IV) from rare earths using functionalized hierarchically mesoporous silica. J. Mater. Sci. 2018, 53, 3398-3416. [CrossRef]

35. Guibal, E.; Roulph, C.; Lecloirec, P. Uranium biosorption by a filamentous fungus Mucor miehei: $\mathrm{pH}$ effect on mechanisms and performances of uptake. Water Res. 1992, 26, 1139-1145. [CrossRef]

36. Singer, D.M.; Guo, H.; Davis, J.A. U(VI) and Sr(II) batch sorption and diffusion kinetics into mesoporous silica (MCM-41). Chem. Geol. 2014, 390, 152-163. [CrossRef]

37. Wang, S.; Vincent, T.; Faur, C.; Guibal, E. Alginate and algal-based beads for the sorption of metal cations: $\mathrm{Cu}(\mathrm{II})$ and $\mathrm{Pb}$ (II). Int. J. Mol. Sci. 2016, 17, 1453. [CrossRef]

38. Wang, S.; Vincent, T.; Faur, C.; Guibal, E. A comparison of palladium sorption using polyethylenimine impregnated alginate-based and carrageenan-based algal beads. Appl. Sci.-Basel 2018, 8, 264. [CrossRef]

39. Wang, S.; Vincent, T.; Faur, C.; Rodriguez-Castellon, E.; Guibal, E. A new method for incorporating polyethyleneimine (PEI) in algal beads: High stability as sorbent for palladium recovery and supported catalyst for nitrophenol hydrogenation. Mater. Chem. Phys. 2019, 221, 144-155. [CrossRef]

40. Wei, Y.; Salih, K.A.M.; Lu, S.; Hamza, M.F.; Fujita, T.; Vincent, T.; Guibal, E. Amidoxime functionalization of algal/polyethyleneimine beads for the sorption of Sr(II) from aqueous solutions. Molecules 2019, 24, 3893. [CrossRef]

41. Hamza, M.F.; Wei, Y.; Guibal, E. Quaternization of algal/PEI beads (a new sorbent): Characterization and application to scandium recovery from aqueous solutions. Chem. Eng. J. 2020, in press. [CrossRef]

42. Wang, S.; Xiao, K.; Mo, Y.; Yang, B.; Vincent, T.; Faur, C.; Guibal, E. Selenium(VI) and copper(II) adsorption using polyethyleneimine-based resins: Effect of glutaraldehyde crosslinking and storage condition. J. Hazard. Mater. 2019, 121637. [CrossRef] [PubMed]

43. Manos, M.J.; Kanatzidis, M.G. Layered metal sulfides capture uranium from seawater. JACS 2012, 134, 16441-16446. [CrossRef]

44. Shao, D.D.; Hou, G.S.; Li, J.X.; Wen, T.; Ren, X.M.; Wang, X.K. PANI/GO as a super adsorbent for the selective adsorption of uranium(VI). Chem. Eng. J. 2014, 255, 604-612. [CrossRef]

45. Hamza, M.F.; Wei, Y.; Mira, H.I.; Abdel-Rahman, A.A.H.; Guibal, E. Synthesis and adsorption characteristics of grafted hydrazinyl amine magnetite-chitosan for $\mathrm{Ni}(\mathrm{II})$ and $\mathrm{Pb}$ (II) recovery. Chem. Eng. J. 2019, 362, 310-324. [CrossRef]

46. Jurado-Lopez, B.; Vieira, R.S.; Rabelo, R.B.; Beppu, M.M.; Casado, J.; Rodriguez-Castellon, E. Formation of complexes between functionalized chitosan membranes and copper: A study by angle resolved XPS. Mater. Chem. Phys. 2017, 185, 152-161. [CrossRef]

47. Sun, Y.B.; Wang, X.X.; Ding, C.C.; Cheng, W.C.; Chen, C.L.; Hayat, T.; Alsaedi, A.; Hu, J.; Wang, X.K. Direct synthesis of bacteria-derived carbonaceous nanofibers as a highly efficient material for radionuclides elimination. ACS Sustain. Chem. Eng. 2016, 4, 4608-4616. [CrossRef]

48. Yuan, S.J.; Xu, F.J.; Kang, E.T.; Pehkonen, S.O. Modification of surface-oxidized copper alloy by coupling of viologens for inhibiting microbiologically influenced corrosion. J. Electrochem. Soc. 2007, 154, C645-C657. [CrossRef]

49. Mishra, S.; Dwivedi, J.; Kumar, A.; Sankararamakrishnana, N. Studies on salophen anchored micro/meso porous activated carbon fibres for the removal and recovery of uranium. RSC Adv. 2015, 5, 33023-33036. [CrossRef]

50. Lu, S.; Chen, L.; Hamza, M.F.; He, C.; Wang, X.; Wei, Y.; Guibal, E. Amidoxime functionalization of a poly(acrylonitrile)/silica composite for the sorption of $\mathrm{Ga}(\mathrm{III})$-Application to the treatment of Bayer liquor. Chem. Eng. J. 2019, 368, 459-473. [CrossRef] 
51. Wang, F.; Li, H.; Liu, Q.; Li, Z.; Li, R.; Zhang, H.; Liu, L.; Emelchenko, G.A.; Wang, J. A graphene oxide/amidoxime hydrogel for enhanced uranium capture. Sci. Rep. 2016, 6, 19367. [CrossRef] [PubMed]

52. Khan, M.A.M.; Khan, W.; Ahamed, M.; Alhazaa, A.N. Microstructural properties and enhanced photocatalytic performance of $\mathrm{Zn}$ doped $\mathrm{CeO}_{2}$ nanocrystals. Sci. Rep. 2017, 7, 12560. [CrossRef] [PubMed]

53. Lopez, E.O.; Rossi, A.L.; Archanjo, B.S.; Ospina, R.O.; Mello, A.; Rossi, A.M. Crystalline nano-coatings of fluorine-substituted hydroxyapatite produced by magnetron sputtering with high plasma confinement. Surf. Coat. Technol. 2015, 264, 163-174. [CrossRef]

54. Ortega-Liebana, M.C.; Chung, N.X.; Limpens, R.; Gomez, L.; Hueso, J.L.; Santamaria, J.; Gregorkiewicz, T. Uniform luminescent carbon nanodots prepared by rapid pyrolysis of organic precursors confined within nanoporous templating structures. Carbon 2017, 117, 437-446. [CrossRef]

55. Yang, K.; Zhong, L.; Guan, R.; Xiao, M.; Han, D.; Wang, S.; Meng, Y. Carbon felt interlayer derived from rice paper and its synergistic encapsulation of polysulfides for lithium-sulfur batteries. Appl. Surf. Sci. 2018, 441, 914-922. [CrossRef]

56. Zhang, Y.W.; Si, R.; Liao, C.S.; Yan, C.H. Facile alcohothermal synthesis, size-dependent ultraviolet absorption, and enhanced CO conversion activity of ceria nanocrystals. J. Phys. Chem. B 2003, 107, 10159-10167. [CrossRef]

57. Chen, S.P.; Hong, J.X.; Yang, H.X.; Yang, J.Z. Adsorption of uranium (VI) from aqueous solution using a novel graphene oxide-activated carbon felt composite. J. Environ. Radioact. 2013, 126, 253-258. [CrossRef]

58. Van den Berghe, S.; Miserque, F.; Gouder, T.; Gaudreau, B.; Verwerft, M. X-ray photoelectron spectroscopy on uranium oxides: A comparison between bulk and thin layers. J. Nucl. Mater. 2001, 294, 168-174. [CrossRef]

59. Fantauzzi, M.; Elsener, B.; Atzei, D.; Rigoldi, A.; Rossi, A. Exploiting XPS for the identification of sulfides and polysulfides. RSC Adv. 2015, 5, 75953-75963. [CrossRef]

60. Hamza, M.F. Grafting of quaternary ammonium groups for uranium(VI) recovery: Application on natural acidic leaching liquor. J. Radioanal. Nucl. Chem. 2019, 322, 519-532. [CrossRef]

61. Wang, F.; Wang, Y.B.; Li, Y.N. Study of influencing factors and the mechanism of preparing triazinedithiol polymeric nanofilms on aluminum surfaces. Int. J. Mol. Sci. 2010, 11, 4715-4725. [CrossRef] [PubMed]

62. Zheng, X.F.; Pan, X.; Nie, Z.Y.; Yang, Y.; Liu, L.Z.; Yang, H.Y.; Xia, J.L. Combined DFT and XPS investigation of cysteine adsorption on the pyrite (100) surface. Minerals 2018, 8, 366. [CrossRef]

63. Song, W.C.; Liu, M.C.; Hu, R.; Tan, X.L.; Li, J.X. Water-soluble polyacrylamide coated-Fe ${ }_{3} \mathrm{O}_{4}$ magnetic composites for high-efficient enrichment of $\mathrm{U}(\mathrm{VI})$ from radioactive wastewater. Chem. Eng. J. 2014, 246, 268-276. [CrossRef]

64. Liu, J.; Zhao, C.S.; Yuan, G.Y.; Li, F.Z.; Yang, J.J.; Liao, J.L.; Yang, Y.Y.; Liu, N. Adsorption behavior of U(VI) on doped polyaniline: The effects of carbonate and its complexes. Radiochim. Acta 2018, 106, 437-452. [CrossRef]

65. Haug, A. Dissociation of alginic acid. Acta Chem. Scand. 1961, 15, 950-952. [CrossRef]

66. Demadis, K.D.; Paspalaki, M.; Theodorou, J. Controlled release of bis(phosphonate) pharmaceuticals from cationic biodegradable polymeric matrices. Ind. Eng. Chem. Res. 2011, 50, 5873-5876. [CrossRef]

67. Marcus, Y. Ion Properties; Marcel Dekker, Inc.: New York, NY, USA, 1997; p. 259.

68. Liu, S.; Yang, Y.; Liu, T.; Wu, W. Recovery of uranium(VI) from aqueous solution by 2-picolylamine functionalized polystyrene-co-maleic anhydride) resin. J. Colloid Interface Sci. 2017, 497, 385-392. [CrossRef]

69. Bayramoglu, G.; Arica, M.Y. MCM-41 silica particles grafted with polyacrylonitrile: Modification in to amidoxime and carboxyl groups for enhanced uranium removal from aqueous medium. Microporous Mesoporous Mater. 2016, 226, 117-124. [CrossRef]

70. He, D.X.; Tan, N.; Luo, X.M.; Yang, X.C.; Ji, K.; Han, J.W.; Chen, C.; Liu, Y.Q. Preparation, uranium (VI) absorption and reuseability of marine fungus mycelium modified by the bis-amidoxime-based groups. Radiochim. Acta 2020, 108, 37-49. [CrossRef]

71. Yang, J.B.; Volesky, B. Biosorption of uranium on Sargassum biomass. Water Res. 1999, 33, $3357-3363$. [CrossRef]

72. Aytas, S.; Turkozu, D.A.; Gok, C. Biosorption of uranium(VI) by bi-functionalized low cost biocomposite adsorbent. Desalination 2011, 280, 354-362. [CrossRef]

73. Zou, W.H.; Zhao, L.; Zhu, L. Efficient uranium(VI) biosorption on grapefruit peel: Kinetic study and thermodynamic parameters. J. Radioanal. Nucl. Chem. 2012, 292, 1303-1315. [CrossRef]

74. Kausar, A.; Bhatti, H.N.; MacKinnon, G. Equilibrium, kinetic and thermodynamic studies on the removal of U(VI) by low cost agricultural waste. Colloids Surf. B 2013, 111, 124-133. [CrossRef] [PubMed] 
75. Nie, X.Q.; Dong, F.Q.; Liu, N.; Zhang, D.; Liu, M.X.; Yang, J.; Zhang, W. Biosorption and biomineralization of uranium(VI) from aqueous solutions by Landoltia punctata. Spectrosc. Spectral Anal. 2015, 35, 2613-2619.

76. Mishra, V.; Sureshkumar, M.K.; Gupta, N.; Kaushik, C.P. Study on sorption characteristics of uranium onto biochar derived from eucalyptus wood. Water Air Soil Pollut. 2017, 228, 309. [CrossRef]

77. Nuhanovic, M.; Grebo, M.; Draganovic, S.; Memic, M.; Smjecanin, N. Uranium(VI) biosorption by sugar beet pulp: Equilibrium, kinetic and thermodynamic studies. J. Radioanal. Nucl. Chem. 2019, 322, 2065-2078. [CrossRef]

78. Venkatesan, K.A.; Shyamala, K.V.; Antony, M.P.; Srinivasan, T.G.; Rao, P.R.V. Batch and dynamic extraction of uranium(VI) from nitric acid medium by commercial phosphinic acid resin, Tulsion CH-96. J. Radioanal. Nucl. Chem. 2008, 275, 563-570. [CrossRef]

79. Semnani, F.; Asadi, Z.; Samadfam, M.; Sepehrian, H. Uranium(VI) sorption behavior onto amberlite CG-400 anion exchange resin: Effects of $\mathrm{pH}$, contact time, temperature and presence of phosphate. Ann. Nucl. Energy 2012, 48, 21-24. [CrossRef]

80. Xu, J.; Chen, M.; Zhang, C.; Yi, Z. Adsorption of uranium(VI) from aqueous solution by diethylenetriamine-functionalized magnetic chitosan. J. Radioanal. Nucl. Chem. 2013, 298, 1375-1383. [CrossRef]

81. Solgy, M.; Taghizadeh, M.; Ghoddocynejad, D. Adsorption of uranium(VI) from sulphate solutions using Amberlite IRA-402 resin: Equilibrium, kinetics and thermodynamics study. Ann. Nucl. Energy 2015, 75, 132-138. [CrossRef]

82. Kou, Y.; Zhang, L.; Liu, B.; Zhu, L.; Duan, T. Phosphonate modified $\mathrm{MoS}_{2}$ composite material for effective adsorption of uranium(VI) in aqueous solution. J. Radioanal. Nucl. Chem. 2020, 323, 641-649. [CrossRef]

83. Su, M.H.; Tsang, D.C.W.; Ren, X.Y.; Shi, Q.P.; Tang, J.F.; Zhang, H.G.; Kong, L.J.; Hou, L.A.; Song, G.; Chen, D.Y. Removal of U(VI) from nuclear mining effluent by porous hydroxyapatite: Evaluation on characteristics, mechanisms and performance. Environ. Pollut. 2019, 254, 112891. [CrossRef]

84. Liu, R.; Wang, Z.-Q.; Liu, Q.-Y.; Luo, F.; Wang, Y.-L. A zinc MOF with carboxylate oxygen-functionalized pore channels for uranium(VI) sorption. Eur. J. Inorg. Chem. 2019, 2019, 735-739. [CrossRef]

85. Mazario, E.; Stemper, J.; Helal, A.S.; Mayoral, A.; Decorse, P.; Losno, R.; Lion, C.; Ammar, S.; Le Gall, T.; Hemadi, M. New iron oxide nanoparticles catechol-grafted with bis(amidoxime)s for uranium(VI) depletion of aqueous solution. J. Nanosci. Nanotechnol. 2019, 19, 4911-4919. [CrossRef] [PubMed]

86. Lazaridis, N.K.; Pandi, T.A.; Matis, K.A. Chromium(VI) removal from aqueous solutions by $\mathrm{Mg}-\mathrm{Al}-\mathrm{CO}_{3}$ hydrotalcite: Sorption-desorption kinetic and equilibrium studies. Ind. Eng. Chem. Res. 2004, 43, 2209-2215. [CrossRef]

87. Lopez-Ramon, M.V.; Stoeckli, F.; Moreno-Castilla, C.; Carrasco-Marin, F. On the characterization of acidic and basic surface sites on carbons by various techniques. Carbon 1999, 37, 1215-1221. [CrossRef]

88. Marczenko, Z. Separation and Spectrophotometric Determination of Elements, 2nd ed.; Ellis Horwood: Chichester, UK, 1986; p. 678.

89. Abu Khoziem, H.A. Mineralogical Characteristics and Leachability of Some Valuable Metals from Abu Zienema Poly-mineralized Carbonaceous Shale, Southwestern Sinai, Egypt. PhD. Thesis, Ain Shams University, Cairo, Egypt, 2017.

90. Tien, C. Adsorption Calculations and Modeling; Butterworth-Heinemann: Newton, MA, USA, 1994; p. 243.

91. Foo, K.Y.; Hameed, B.H. Insights into the modeling of adsorption isotherm systems. Chem. Eng. J. 2010, 156, 2-10. [CrossRef]

92. Gustafsson, J.P. Visual MINTEQ Version 3.0; KTH, Department of Land and Water Recources: Stockholm, Sweden, 2013; Available online: https://vminteq.lwr.kth.se/ (accessed on 2 February 2020).

(C) 2020 by the authors. Licensee MDPI, Basel, Switzerland. This article is an open access article distributed under the terms and conditions of the Creative Commons Attribution (CC BY) license (http://creativecommons.org/licenses/by/4.0/). 